\title{
Novel composites of $\beta$-SiAION and radome manufacturing technology developed at ARCI, Hyderabad, for hypervelocity vehicles
}

\author{
IBRAM GANESH \\ Centre of Excellence for Advanced Ceramics, International Advanced Research Centre for Powder Metallurgy and New \\ Materials (ARCI), Hyderabad 500 005, India \\ ibramganesh@arci.res.in; dribramganesh@gmail.com
}

MS received 11 February 2016; accepted 4 October 2016; published online 8 July 2017

\begin{abstract}
Keeping the importance of developing suitable radome (a word derived from radar + dome) materials and near-net shape consolidation technique for manufacturing radomes suitable for hypersonic ( $>$ mach 5) radar-guided missiles in India, the International Advanced Research Centre for Powder Metallurgy and New Materials (ARCI), Hyderabad, has initiated an in-house R\&D programme and successfully developed a complete process know-how for manufacturing defect-free prototype $\beta$-SiAlON-based radome structures with all the desired properties. As a part of this R\&D programme, total six separate sub-projects mentioned below were undertaken and executed: (i) identification of the best composition out of $\beta-\mathrm{Si}_{6-z} \mathrm{Al}_{z} \mathrm{O}_{z} \mathrm{~N}_{8-z}(0 \leq z \leq 4.1)$ solid solution, which possesses a right combination of properties required for radome applications, (ii) designing of an AlN-free precursor mixture for consolidating $\beta-\mathrm{Si}_{4} \mathrm{Al}_{2} \mathrm{O}_{2} \mathrm{~N}_{6}$ ceramics by following aqueous colloidal processing routes, (iii) development of a process for passivating water-sensitive AlN powder against hydrolysis, (iv) development of aqueous gelcasting (GC) and hydrolysis-assisted solidification (HAS) powder processing routes for consolidating dense $\beta$-SiAlON ceramics using highly solids loaded ( $>50 \mathrm{vol} \%$ ) aqueous slurries, (v) development of an hydrolysis-induced aqueous gelcasting (GCHAS) process, a novel near-net-shape consolidation technique, to produce radomes with very high-production yields and (vi) development of an economic route for synthesizing the low-dielectric constant and high strength novel $\beta-\mathrm{SiAlON}-\mathrm{SiO}_{2}$ ceramic composites. In this paper, (i) the basis for choosing $\beta-\mathrm{SiAlON}-$ based ceramics for hypervelocity radome applications, and (ii) the various bottle-neck problems faced, while executing this entire R\&D work and the way they were overcome have been critically analysed and discussed systematically, while citing all the relevant and important references.
\end{abstract}

Keywords. Hypervelocity radome; $\beta$-SiAlON; ceramic composite; near-net-shape consolidation; AlN passivation against hydrolysis; conformal sintering.

\section{Introduction}

Janney et al's [1] paper 'Gelcasting SiAlON radomes', published in 2004 from Oak Ridge National Laboratory, USA, was the basis for initiating an R\&D project at ARCI, Hyderabad, and aiming at developing complete process know-how for manufacturing of defect-free prototype $\beta$-SiAlON-based ceramic radomes suitable for hypersonic radar-guided missile applications (figure 1). The $\beta$-SiAlON composition selected for radomes that were manufactured in the process reported by Janney et al [1-3] was termed as GD-1 (general dynamics1) (figure 2). The sintered characteristics of GD-1 (table 1) [1] were set as target properties for the R\&D project started at ARCI, Hyderabad. GD-1 radomes were developed for advanced medium range air-to-air missile (AMRAAM) and standard missile systems in USA [2,3]. For the first time, an aqueous gelcasting process was designed and successfully employed for consolidating thin wall $\beta$-SiAlON-based radome structures (figures 3 and 4) with near-net shape using AlN (which decomposes into ammonia and alumina when comes into contact with water) as one of the starting raw materials [1-3]. However, this reported gelcasting process was found to be not suitable to manufacture $\beta$ SiAlON radomes by utilizing raw materials supplied by all other manufacturers [4-22]. The gelcasting (50 vol\% solids loaded) slurries prepared by dispersing desired amounts of $\alpha-\mathrm{Si}_{3} \mathrm{~N}_{4}(\mathrm{P} 95 \mathrm{H}$, VESTA Ceramics AB, Sweden), $\alpha-$ $\mathrm{Al}_{2} \mathrm{O}_{3}$ (ACC Thane, India), AlN (Grade AT, H.C. Starck, Germany) surface-treated against hydrolysis by following a process developed at ARCI, Hyderabad [11,13,18-22], and $\mathrm{Y}_{2} \mathrm{O}_{3}$ (Rhodia Inc., Phoenix, Arizona) (sintering aid) in an organic pre-mix solution obtained upon dissolution of gelcasting organic monomers (methacrylamide (MAM), methylenebisacrylamide (MBAM) and n-vinylpyrrolidinone (NVP) in 2:2:1 ratio) in water did not solidify on addition of the suggested amounts of polymerization initiator (10 wt $\%$ aqueous solution of ammonium persulfate, APS) and catalyst (as-purchased tetramethylethylenediammine, TEMED) 


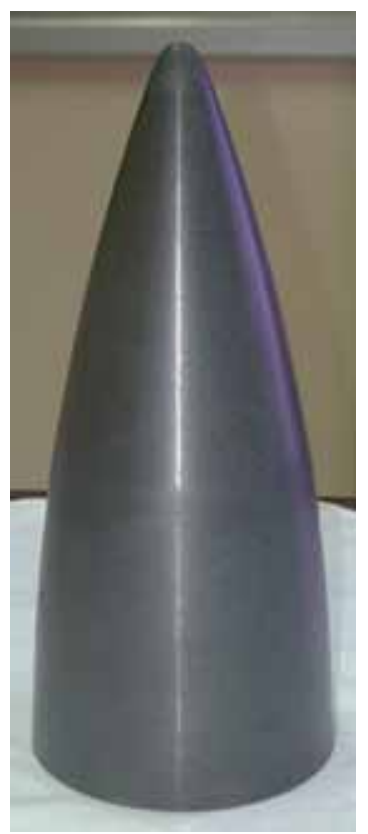

Figure 1. A digital photograph of sintered and machined thin walls (about $4 \mathrm{~mm}$ thick) of $\beta$-SiAlON prototype radome manufactured at ARCI, Hyderabad.

system by Janney et al [1-3]. It appears that the polymerization initiator and catalyst did not react with MAM, MBAM and NVP gelcast organic monomers in the presence of these ceramic powders mixture to facilitate the gelling of the slurries after casting in non-porous (petroleum jelly-coated plastic as well as aluminium metal) moulds $[11,13,18-22]$. We came to this conclusion based on the fact that when the same gelcasting system was employed for consolidating alumina (figure 5) [10], $\mathrm{MgAl}_{2} \mathrm{O}_{4}$ spinel (figure 6) [11-15] and ZTA ceramics [16-18], it worked absolutely fine. Furthermore, the water processable AlN powder (ART Inc., Buffalo, NY, USA), which was employed by Janney et al [1-3] in their process, while consolidating $\beta$-SiAlON-based radome structures, was stopped supplying by the manufacturer. Another major limitation of the reported gelcasting process is the very low production yield of radome manufacturing process, which is not sufficient for starting a production facility for manufacturing radomes based on their processes [1-3]. The main reason for this poor radome production yield was the insufficient strength conferred by the gelcasting monomers premix solution to the gels formed out of the colloidal slurries after introducing the polymerization initiator and catalyst. Due to this insufficient gel strength, the green radomes are very difficult to remove off the moulds without breaking. Apart from poor gel strength, the cast radome body also did not dry uniformly throughout the body as the nose portion is still wet, while the rest of the body is completely dried as the wall thickness of the nose portion is much thicker than the rest of the body. This non-uniform drying pattern often leads to breaking of the nose portion of the green radomes, leading to very low product yields $[1,19]$. In addition to these, why the particular GD-1 composition was chosen out of wide solidsolution of $\beta-\mathrm{Si}_{6-z} \mathrm{Al}_{z} \mathrm{O}_{z} \mathrm{~N}_{8-z}$ (where $0 \leq z \leq 4$.1) for making radome structures and why it showed the best combination of properties as required by radomes employed in AMRAAM and standard missile systems was also not revealed by Janney et al [1-3].

In view of the above reasons, the first objective of the R\&D work started at ARCI, Hyderabad, for developing radome manufacturing technology for hypersonic missile applications was to identify the best composition out of wide-range solid solution of $\beta-\mathrm{Si}_{6-z} \mathrm{Al}_{z} \mathrm{O}_{z} \mathrm{~N}_{8-z}(0 \leq z \leq 4.1)$ for achieving desired properties for radome applications. Then, the second important objective for this project was to design (or formulate) an AlN-free precursor mixture to obtain the best composition identified as a part of the first objective of this project. This AlN-free precursor mixture composition is required to consolidate thin wall $\beta$-SiAlON-based radome structures with near-net shape by following aqueous colloidal processing routes, and as water processable AlN powder is not available in the market. However, while doing the R\&D work to meet the above-mentioned two-objectives of the project, another four separate sub-projects (total six separate projects) were also needed to be undertaken and executed them before manufacturing the defect-free dense prototype thin-wall $\beta$ SiAlON-based radome structures with very high production yields ( $>95 \%$ ) and with all the desired properties. The necessity for undertaking those six separate sub-projects, and how the results obtained in these six sub-projects have helped in producing the defect-free prototype $\beta$-SiAlON-based radome structures suitable for hypervelocity missile applications are presented and discussed in this paper.

Really, it is quite difficult to fabricate thin-wall $(<5 \mathrm{~mm}$ thick) structures, such as radomes, crucibles, etc., by following aqueous colloidal processing routes in comparison to structures, such as pellets, bricks, rings, etc., because the slurry needs to be completely solidified inside the mould after casting with sufficiently high green strength, otherwise, the component will break, while removing off the mould. To fabricate such thin-wall structures by following these colloidal processing routes, the slurry solidification mechanism should be very effective, and such green strength was conferred to the thin-wall structures like radomes, crucibles, etc., only by a novel hydrolysis induced aqueous gelcasting (GCHAS) process developed as a part of this project [11,13,18-22]. This latter GCHAS process is a combination of the conventional aqueous gelcasting (GC) process [1-3] and the hydrolysisassisted solidification (HAS) route [23,24]. Hence, it can show the synergistic benefits offered by both GC and HAS processes to the bodies which were consolidated following this new route.

\section{Fixing $\beta$-SiAION composition for radome applications}

Radome is employed to protect the antenna used in a radarguided missile to transmit radar signals (i.e., electromagnetic 


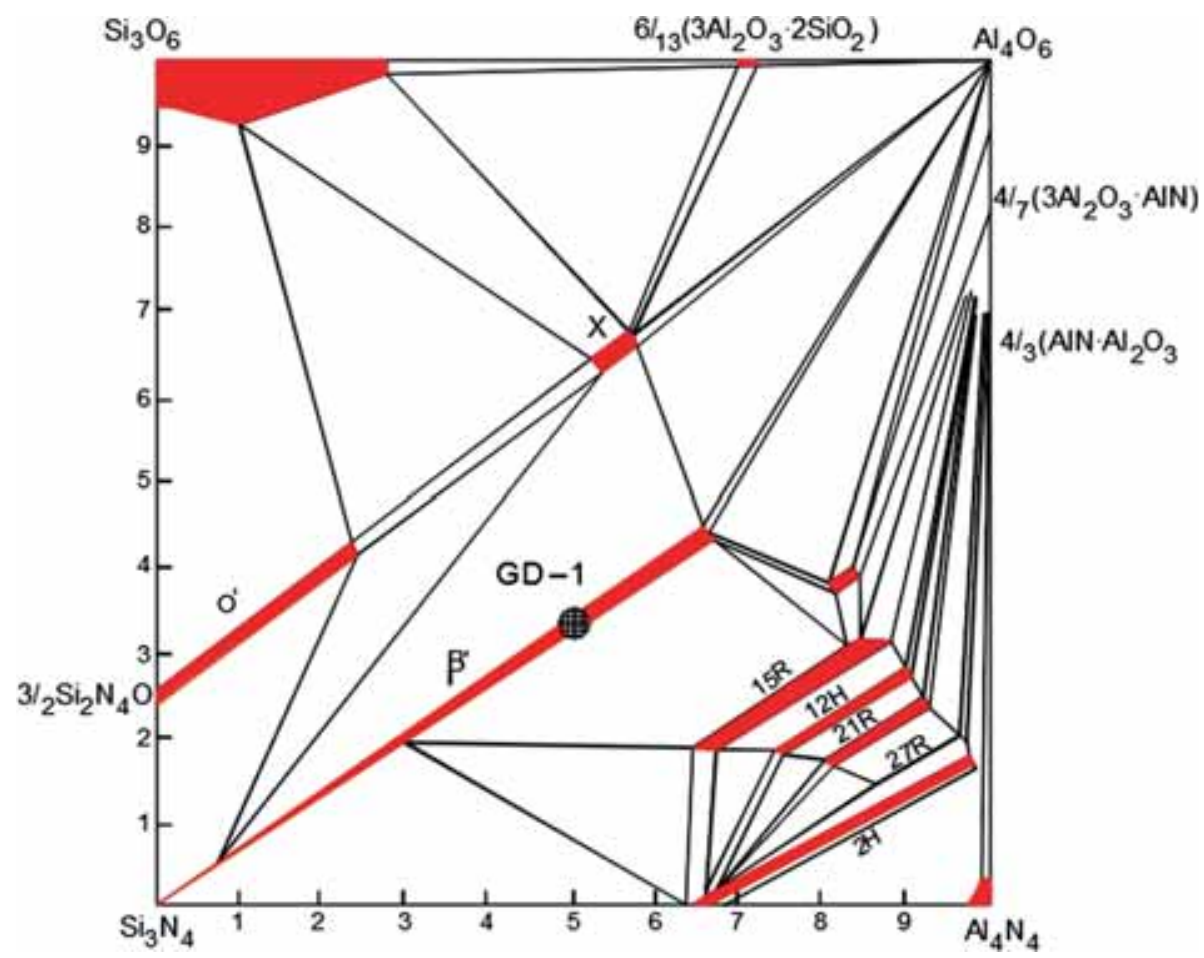

Figure 2. Quaternary phase diagram encompassing general dynamics-1 (GD-1) [1].

Table 1. The target properties to be met by the materials developed at ARCI, Hyderabad, as a part of developing radome manufacturing technology for hypervelocity missile applications [1].

\begin{tabular}{lc}
\hline Property & Value \\
\hline Strength $(\sigma)$ at $25^{\circ} \mathrm{C}$ & $38 \mathrm{ksi}$ \\
Elastic modulus $(E)$ & $34 \times 10^{6} \mathrm{psi}$ \\
Knoop hardness & 1300 \\
Density $(\rho)$ & $3.02 \mathrm{~g} \mathrm{~cm}^{-3}$ \\
Maximum use temperature & $>1500^{\circ} \mathrm{C}$ \\
Coefficient of thermal expansion $(\mathrm{CTE})(\alpha)$ & \\
at $25^{\circ} \mathrm{C}$ & $1.8 \times 10^{-6}{ }^{\circ} \mathrm{C}^{-1}$ \\
at $1000^{\circ} \mathrm{C}$ & $4.1 \times 10^{-6}{ }^{\circ} \mathrm{C}^{-1}$ \\
Thermal conductivity $(\kappa)$ & $16.0 \mathrm{~W} \mathrm{\textrm {K } ^ { - 1 }}$ \\
Thermal shock $(\sigma \kappa / \mathrm{E} \alpha)$ & 9935 \\
Dielectric constant $(\varepsilon)$ & $6.84-7.46$ \\
at $25^{\circ} \mathrm{C}$ & $7.00-7.66$ \\
at $1000^{\circ} \mathrm{C}$ & \\
Loss tangent $(\tan \delta)$ & $0.0013-0.002$ \\
at $25^{\circ} \mathrm{C}$ & $0.003-0.004$ \\
at $1000^{\circ} \mathrm{C}$ & \\
\hline
\end{tabular}

waves) between the missile and the radar system. Furthermore, to withstand the severe aero-thermal loads during missile takeoff operation, while transmitting the sent electromagnetic signals from radar without any disturbance, the radome material should possess (i) a stable, low dielectric permittivity $v s$. temperature (the lower is the better), (ii) a low loss tangent up to high temperature, (iii) a high strength at ambient and high temperatures, (iv) a high elastic modulus to keep the thin-walled radome from buckling, (v) a high thermal shock resistance, and (vi) all weather capability 


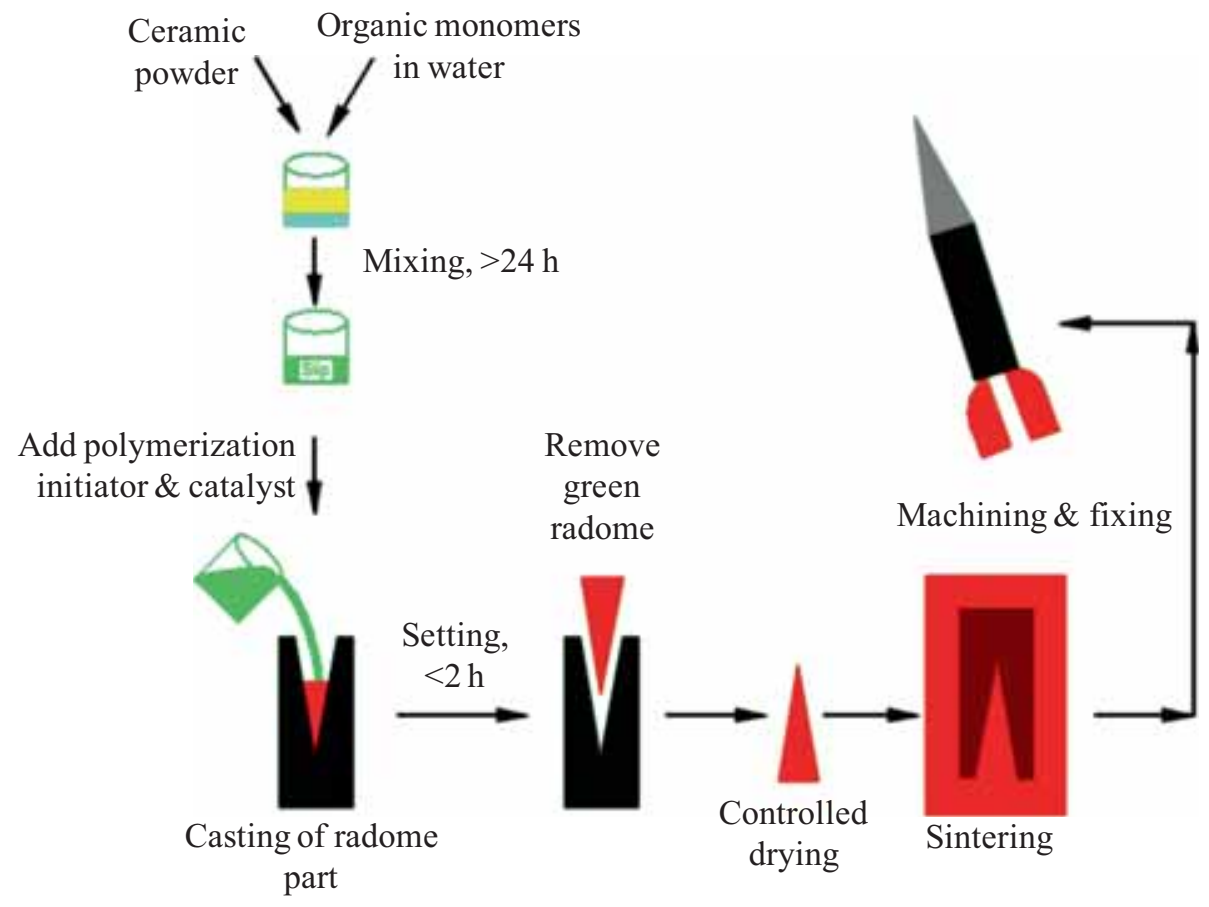

Figure 3. Gelcasting and thermal processes employed for manufacturing radome structures by following near-net-shape aqueous gelcasting route [1].

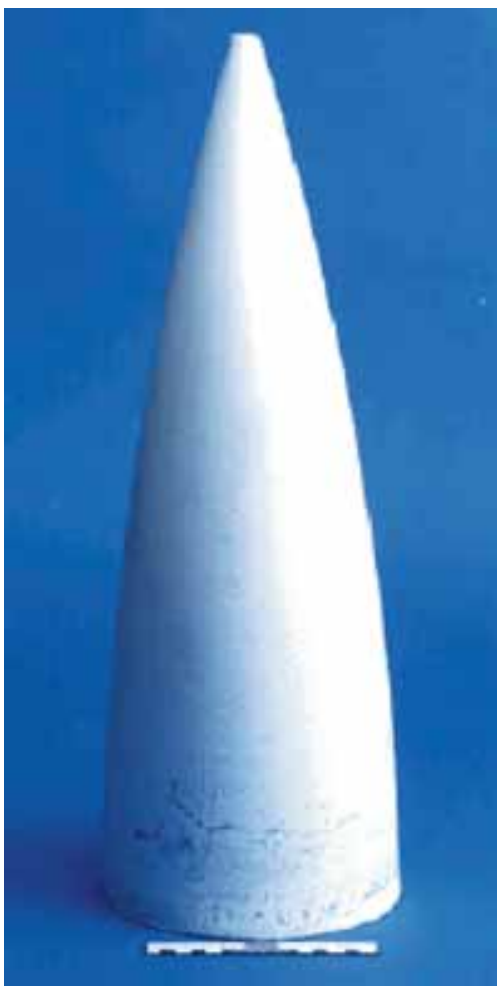

Figure 4. Photo of gelcast green body of radome manufactured by Janney et al [1], at Oak Ridge National Laboratory, USA. The presence of processing defects formed during setting of the slurry at the bottom portion of the radome can be noticed. (rain erosion, particle impact resistance, etc.) [1-3,5,6,2527]. In the case of hypersonic radomes (i.e., those travel at a speed of $>$ Mach 5 or $>5$ times of speed of sound in air), the additional quality required is a high temperature $\left(>1370^{\circ} \mathrm{C}\right)$ withstanding capability. Initially, fused silica [26], Pyroceram 9606 and Rayceram 8 [3], barium aluminium silicate [28], aluminium phosphate (commercially known as Cerablak $^{\mathrm{TM}}$ (which is being manufactured and supplied by Applied Thin Films Inc., Evanston, IL, USA) [29,30], $\mathrm{SiO}_{2}-$ AlN ceramics [31], $\mathrm{SiO}_{2}-\mathrm{BN}$ ceramics [32], reaction-bonded silicon nitride [33] and liquid-phase sintered silicon nitride [21], silicon nitride nano-composite [25], etc., were considered for these applications, but finally, $\beta-\mathrm{Si}_{4} \mathrm{Al}_{2} \mathrm{O}_{2} \mathrm{~N}_{4}$ has been identified as the best material for these hypervelocity vehicle applications [1-3]. Furthermore, the ceramic components out of these latter composition can be consolidated by following relatively easier colloidal processing techniques to confer near-net shape in comparison to other candidate radome materials $[1-3,5,6,25-27,34,37]$. To identify the right $\beta$-SiAlON composition out of $\beta-\mathrm{Si}_{6-z} \mathrm{Al}_{z} \mathrm{O}_{z} \mathrm{~N}_{8-z}(0 \leq z \leq$ 4.1) wide solid solution for these targeted radome applications, we have formulated seven different compositions (where $z=1,1.5,2,2.5,3,3.5$ and 4), which cover the entire solid solution by using high-purity $\alpha-\mathrm{Si}_{3} \mathrm{~N}_{4}(\mathrm{P} 95 \mathrm{H}$, VESTA Ceramics AB, Sweden), $\alpha-\mathrm{Al}_{2} \mathrm{O}_{3}$ (HP, ACC India Limited, India) and AlN (Grade AT, H.C. Starck, Germany) as starting precursor powders. Three different concentrations of $\mathrm{Y}_{2} \mathrm{O}_{3}$ (Rhodia Inc., Phoenix, Arizona) (3, 5 and $7 \mathrm{wt} \%$ ) 


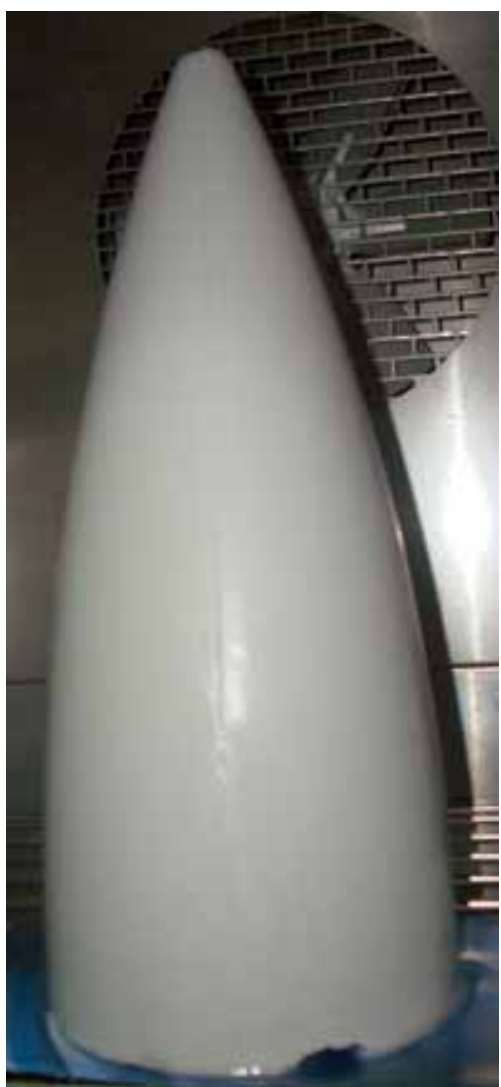

Figure 5. A green radome (about $290 \mathrm{~mm}$ height and $125 \mathrm{~mm}$ base diameter) consolidated from a $50 \mathrm{vol} \%$ of alumina-loaded slurry in a split-type Teflon-lined aluminium mould. This radome shape is made to demonstrate the net-shape consolidation capability of GCHAS colloidal processing route [10].

were employed as a sintering aid. Hence, totally 21 different types of $\beta$-SiAlON compositions were formulated in this study [38].

In a typical experiment, $\sim 200 \mathrm{ml}$ sulfur-free toluene (AR Grade, Loba-Chemie, India) was taken in a $500 \mathrm{ml}$ alumina bowl to which $\sim 200$ g precursor powder mixture (all $21 \mathrm{com}$ positions separately), $\sim 60 \mathrm{~g}$ of $5 \mathrm{wt} \%$ aqueous PVA solution and $\sim 200 \mathrm{~g} \mathrm{ZrO}_{2}$ cylindrical pebbles $(10 \mathrm{~mm}$ diameter and $12 \mathrm{~mm}$ length) were introduced and grounded for $\sim 30 \mathrm{~min}$ in a planetary ball mill (Retsch, Germany) by maintaining $200 \mathrm{rpm}$. The resultant dough was separated from toluene, dried at $\sim 90^{\circ} \mathrm{C}$ for $12 \mathrm{~h}$ in an electrically heated oven and passed through a -30 BSS mesh to obtain granules with less than $595 \mu \mathrm{m}$ prior to pressing into pellets $(30 \mathrm{~mm}$ diameter and $7 \mathrm{~mm}$ thickness) under a pressure of $200 \mathrm{MPa}$. To make 3-point-bend test samples, $\sim 80 \mathrm{~mm}$ diameter discs with about $7 \mathrm{~mm}$ thickness were also pressed under $200 \mathrm{MPa}$ pressure, sintered along with $30 \mathrm{~mm}$ diameter samples and then cut into required sizes. Binder burnout was operated at $500^{\circ} \mathrm{C}$ for $1 \mathrm{~h}$ prior to final sintering at $1675-1700^{\circ} \mathrm{C}$ for $4 \mathrm{~h}$ under $\sim 800$ torr $\mathrm{N}_{2}$ atmosphere. During sintering, the pressed pellets were covered with $\mathrm{Si}_{3} \mathrm{~N}_{4}-\mathrm{BN}$ powder mixture

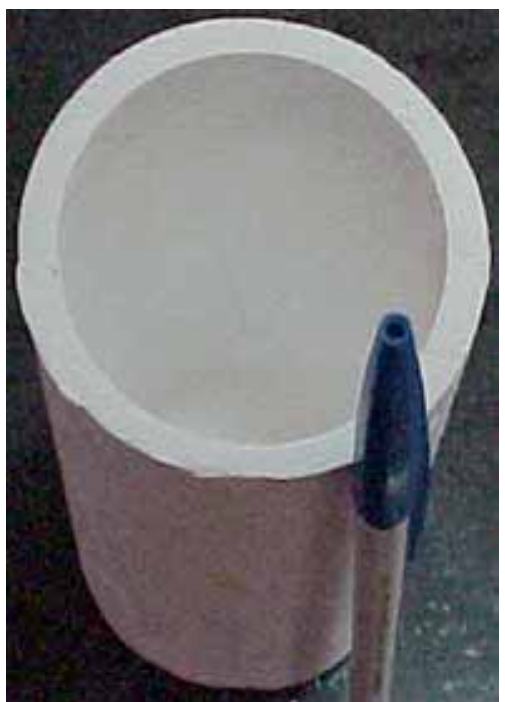

Figure 6. Dried green (not sintered) $\mathrm{MgAl}_{2} \mathrm{O}_{4}$ spinel crucible (500 $\mathrm{ml}$ capacity) consolidated by following an aqueous gelcasting of a slurry containing $45 \mathrm{vol} \%$ solids loading. This crucible shape is made to demonstrate the net-shape consolidation capability of GCHAS colloidal processing route out of water sensitive $\mathrm{MgAl}_{2} \mathrm{O}_{4}$ spinel powder. Prior to prepare colloidal suspension, the $\mathrm{MgAl}_{2} \mathrm{O}_{4}$ spinel powder was surface-passivated against hydrolysis by following a process developed at ARCI, Hyderabad [11-15].

$\left(50 \% \mathrm{Si}_{3} \mathrm{~N}_{4}\right.$ and $\left.50 \% \mathrm{BN}\right)$ to protect them from decomposition and/or deformation. These sintered $\beta$-SiAlON ceramics were characterized for bulk density (BD), apparent porosity (AP), water absorption (WA) capacity, phase formation, microstructure, coefficient of thermal expansion (CTE), hardness, fracture toughness, 3-point bend strength and dielectric constant at 16-18 GHz frequency. Thus, obtained results were published elsewhere [38]. The sintered properties suggested that an increase in $z$ value, $\mathrm{Y}_{2} \mathrm{O}_{3}$ concentration and sintering temperature have resulted in increase of $\beta$-SiAlON phase formation, $\mathrm{BD}$, grain size growth, fracture toughness, dielectric constant, and decrease of AP, WA capacity, hardness, and 3 -point bend strength. We are yet to analyse the underlying mechanisms in achieving these property variations with these varying chemical compositions and reaction sintering conditions. A stable and low dielectric constant values (5.677.67) between 16 and $18 \mathrm{GHz}$ frequencies are measured for these sintered $\beta$-SiAlON ceramics [38]. The $\beta-\mathrm{Si}_{4} \mathrm{Al}_{2} \mathrm{O}_{2} \mathrm{~N}_{6}$ sintered at $1675^{\circ} \mathrm{C}$ for $4 \mathrm{~h}$ using $7 \mathrm{wt} \% \mathrm{Y}_{2} \mathrm{O}_{3}$ exhibited a $\mathrm{BD}$ of $\sim 3.06 \mathrm{~g} \mathrm{ml}^{-1}$, AP of $\sim 0.01 \%$, WA capacity of $\sim 0.01$, $\sim 94.43 \%$ of $\beta$-SiAlON phase, a hardness of $\sim 1317 \mathrm{~kg} \mathrm{~mm}^{-2}$, a fracture toughness of $\sim 3.30 \mathrm{MPa} \mathrm{m}^{-1 / 2}$, a 3-point bend strength of $\sim 226 \mathrm{MPa}$, a CTE of $3.628 \times 10^{-6}{ }^{\circ} \mathrm{C}^{-1}$ between 30 and $700^{\circ} \mathrm{C}$, and a dielectric constant of $\sim 7.206$ at $17 \mathrm{GHz}$. Among the sintered properties of total 21 different $\beta$-SiAlON ceramic compositions investigated in this study, these are the best combination of properties noted [38]. It is a wellknown fact in the literature that lower dielectric constant and 
dielectric loss values together with higher temperature withstanding capability, higher fracture toughness, lower CTE, higher hardness, higher theoretical density, lower BD, lower WA capacity and lower AP are preferred by a radome material [1-3].

As noted above, the $\beta-\mathrm{Si}_{4} \mathrm{Al}_{2} \mathrm{O}_{2} \mathrm{~N}_{6}$ sintered with $7 \mathrm{wt} \%$ $\mathrm{Y}_{2} \mathrm{O}_{3}$ at $1675^{\circ} \mathrm{C}$ for $4 \mathrm{~h}$ was chosen to manufacture radome structures by following aqueous colloidal near-net-shape consolidation techniques. Incidentally, $\beta-\mathrm{Si}_{4} \mathrm{Al}_{2} \mathrm{O}_{2} \mathrm{~N}_{6}$ is the same composition named as GD-1 by Janney et al $[1-3,38]$. It is understood that to process any ceramic component by following aqueous gelcasting route, all the precursor (i.e., starting) materials should be of water processable (i.e., they should not react with water). In the present case, AlN undergoes decomposition upon following the aqueous colloidal processing route. As $\beta-\mathrm{Si}_{4} \mathrm{Al}_{2} \mathrm{O}_{2} \mathrm{~N}_{6}$ requires $\mathrm{AlN}$ as one of the starting materials $\left((6-z) \mathrm{Si}_{3} \mathrm{~N}_{4}+z \mathrm{Al}_{2} \mathrm{O}_{3}+z \mathrm{AlN} \leftrightarrow\right.$ $3 \mathrm{Si}_{6-z} \mathrm{Al}_{z} \mathrm{O}_{z} \mathrm{~N}_{8-z}$, where $\left.0 \leq z \leq 4.1\right)[37,39]$, it is quite difficult to process this particular GD-1 composition by following aqueous gelcasting routes as AlN decomposes into ammonia and aluminium hydroxide when it comes into contact with water $\left(\mathrm{AlN}+3 \mathrm{H}_{2} \mathrm{O} \rightarrow \mathrm{Al}(\mathrm{OH})_{3}+\mathrm{NH}_{3}\right)[15,23,40$ 46]. This AlN decomposition causes (i) the overall change in the chemical composition of $\beta-\mathrm{Si}_{4} \mathrm{Al}_{2} \mathrm{O}_{2} \mathrm{~N}_{6}$, hence, the final properties of the radome, (ii) the coagulation of the particulate suspension as $\mathrm{pH}$ of the suspension undergoes changes with the release of ammonia by the decomposition of AlN, and (iii) the setting of particulate suspension (i.e., slurry) within the vessel used for mixing the precursor mixture containing aqueous gelcast pre-mix solution by ball milling process, which is difficult to remove off $[1,3]$.

\section{Formulation of AIN-free precursor mixture for $\beta-\mathrm{Si}_{4} \mathrm{Al}_{2} \mathrm{O}_{2} \mathrm{~N}_{6}$ ceramics}

Since the water processable AlN powder was not available in the market, we have tried to find an $\mathrm{AlN}$-free precursor mixture that gives exact $\beta-\mathrm{Si}_{4} \mathrm{Al}_{2} \mathrm{O}_{2} \mathrm{~N}_{6}$ composition or very close to it upon the conventional reaction sintering process in the absence of external pressure. We found, only one precursor mixture composition $\left(\mathrm{Si}_{3} \mathrm{~N}_{4} / \mathrm{Al}_{2} \mathrm{O}_{3}=1.5\right)$ that gives $\beta-\mathrm{Si}_{4} \mathrm{Al}_{2} \mathrm{O}_{2} \mathrm{~N}_{6}$ with an excess of $0.5 \mathrm{~mol} \%$ (i.e., about $9 \mathrm{wt} \%$ ) $\mathrm{SiO}_{2}\left(1.5 \mathrm{Si}_{3} \mathrm{~N}_{4}+\mathrm{Al}_{2} \mathrm{O}_{3} \rightarrow \beta-\mathrm{Si}_{4} \mathrm{Al}_{2} \mathrm{O}_{2} \mathrm{~N}_{6}+0.5 \mathrm{SiO}_{2}\right)$ upon reaction sintering at elevated temperatures. Interestingly, this in situ generated silica can reduce the dielectric constant and CTE of $\beta-\mathrm{Si}_{4} \mathrm{Al}_{2} \mathrm{O}_{2} \mathrm{~N}_{6}$ considerably as silica possesses relatively low CTE $\left(<2 \times 10^{-6}{ }^{\circ} \mathrm{C}^{-1}\right)$ and low dielectric constant $(<4)$. In a study, a similar kind of silicon oxynitride ( $\mathrm{SiON}$ ) nano-composite was prepared by calcining the $\alpha-\mathrm{Si}_{3} \mathrm{~N}_{4}$ powder in an open-air atmosphere at $1700^{\circ} \mathrm{C}$ followed by sintering at $>1800^{\circ} \mathrm{C}$ in the nitrogen atmosphere after compacting [25]. This latter sintered $\mathrm{SiON}$ material exhibited a dielectric constant of 4.78 at $25^{\circ} \mathrm{C}$ and 5.0 at $1000^{\circ} \mathrm{C}$, and a loss tangent

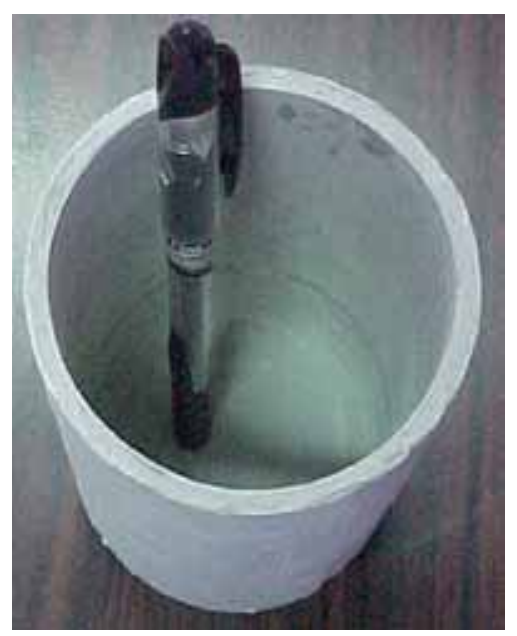

Figure 7. A digital photograph of $\sim 500 \mathrm{ml}$ capacity green crucible made by following an aqueous gelcasting route using slurries containing $48 \mathrm{vol} \% \beta-\mathrm{Si}_{4} \mathrm{Al}_{2} \mathrm{O}_{2} \mathrm{~N}_{6}-0.5 \mathrm{SiO}_{2}$ precursor mixture [47].

of 0.0014 at $25^{\circ} \mathrm{C}$. However, the major disadvantage associated with this SiON material is the difficulty in controlling its final chemical composition as it depends on the extent of surface oxidation of silicon nitride that takes place during calcination processes instead of the composition of the starting raw materials like $\beta-\mathrm{Si}_{4} \mathrm{Al}_{2} \mathrm{O}_{2} \mathrm{~N}_{6}$ depends on raw materials, but not on the sintering atmosphere. In the case of $\mathrm{Si}_{3} \mathrm{~N}_{4} / \mathrm{Al}_{2} \mathrm{O}_{3}(=1.5)$ precursor mixture, the final composition (i.e., $\beta-\mathrm{Si}_{4} \mathrm{Al}_{2} \mathrm{O}_{2} \mathrm{~N}_{6}-0.5 \mathrm{SiO}_{2}$ ), directly comes from precursor mixture itself, and there would not be processing problems as can be noted during the synthesis of SiON $[25,47]$. In view of these advantages, we could successfully consolidate $\mathrm{Si}_{3} \mathrm{~N}_{4} / \mathrm{Al}_{2} \mathrm{O}_{3}(=1.5)$ precursor mixture using $\mathrm{Y}_{2} \mathrm{O}_{3}(3-7$ $\mathrm{wt} \%)$ as a sintering aid by following an aqueous gelcasting and then sintering for $2-4 \mathrm{~h}$ at $1675-1800^{\circ} \mathrm{C}$ [1]. The characteristics of these sintered $\beta-\mathrm{Si}_{4} \mathrm{Al}_{2} \mathrm{O}_{2} \mathrm{~N}_{6}-0.5 \mathrm{SiO}_{2}$ ceramics are published in ref. [47]. The aqueous particulate slurry containing 48 vol\% $\beta-\mathrm{Si}_{4} \mathrm{Al}_{2} \mathrm{O}_{2} \mathrm{~N}_{6}-0.5 \mathrm{SiO}_{2}$ precursor mixture was also gelcast in an indigenously designed and fabricated aluminum mould to fabricate defect-free crucibles of $500 \mathrm{ml}$ volume (figure 7) [47]. The gelcast $\beta-\mathrm{Si}_{4} \mathrm{Al}_{2} \mathrm{O}_{2} \mathrm{~N}_{6}-0.5 \mathrm{SiO}_{2}$ obtained from a slurry containing 48 vol\% solids exhibited a BD of $3.13 \mathrm{~g} \mathrm{~cm}^{-3}, \beta$-SiAlON phase of $\sim 90 \%$, CTE of $3.197 \times 10^{-6}{ }^{\circ} \mathrm{C}^{-1}$ (between 30 and $1000^{\circ} \mathrm{C}$ ), fracture toughness of $\sim 3.42 \mathrm{MPa} \mathrm{m}^{-1 / 2}$, a 3-point bend strength of $\sim 199 \mathrm{MPa}$, dielectric constant of $\sim 6.32$ at $17 \mathrm{GHz}$ frequency after sintering for $4 \mathrm{~h}$ at $1750^{\circ} \mathrm{C}$ with $7 \mathrm{wt} \% \mathrm{Y}_{2} \mathrm{O}_{3}$ [47].

Although the formulation of $\mathrm{Si}_{3} \mathrm{~N}_{4} / \mathrm{Al}_{2} \mathrm{O}_{3}(=1.5)$ could be successfully processed into defect-free sintered $\beta-\mathrm{Si}_{4} \mathrm{Al}_{2} \mathrm{O}_{2}$ $\mathrm{N}_{6}-0.5 \mathrm{SiO}_{2}$ radome structures, the 3-point bend strength of this composite has been estimated to be only about $199 \mathrm{MPa}$, which is a low value [47]. If the strength value is low, then the dielectric constant value also should be low, so that thicker walls can be used for radome manufacturing. If strength is 
low and dielectric constant is high, then thinner walls have to be used, which is difficult while manufacturing the actual size radomes with about $>1 \mathrm{~m}$ height and a base of $>50 \mathrm{~cm}$ width [21]. Since the stoichiometric $\beta-\mathrm{Si}_{4} \mathrm{Al}_{2} \mathrm{O}_{2} \mathrm{~N}_{6}$ consolidated by following conventional dry-powder pressing (CDPP) route exhibited a higher sintered 3-point bend strength (about $226 \mathrm{MPa}$ ) and a dielectric constant of about 7.206 at 17 $\mathrm{GHz}$ [38], we have tried to make the same stoichiometric $\beta-\mathrm{Si}_{4} \mathrm{Al}_{2} \mathrm{O}_{2} \mathrm{~N}_{6}$ radome by following aqueous gelcasting process for which the water processable $\mathrm{AlN}$ powder is required [48].

\section{Surface passivation of AIN powder against hydrolysis}

Developing a process for passivating AlN powder against hydrolysis is of great importance not only for making $\beta$ SiAlON-based components, but also for making several near-net-shape AlN and AlON components by following inexpensive and environmentally friendly aqueous colloidal processing routes [42]. At present, AlN-based components for commercial applications are made following a CDPP route and then sintered to achieve full density and after that they were subjected to an extensive and expensive machining to obtain the desired final shapes [49,51]. Furthermore, relatively high density and high uniformity, and thus, high reliability of performance is difficult to achieve for ceramics consolidated by CDPP route. Hence, colloidal processing routes are recommended for fabricating such a high end product. AlN powder not only decomposes when it comes into contact with water, but also upon long time storage due to its poor resistance to hydrolysis (i.e., shelf life is very low). Upon storage, AlN powder surface reacts with water vapour according to equations (1)-(3).

$$
\begin{aligned}
& \mathrm{AlN}+2 \mathrm{H}_{2} \mathrm{O} \rightarrow \mathrm{AlOOH}_{\text {amorph }}+\mathrm{NH}_{3}, \\
& \mathrm{NH}_{3}+\mathrm{H}_{2} \mathrm{O} \leftrightarrow \mathrm{NH}_{4}^{+}+\mathrm{OH}^{-}, \\
& \mathrm{AlOOH}_{\text {amorph }}+\mathrm{H}_{2} \mathrm{O} \rightarrow \mathrm{Al}(\mathrm{OH})_{3} .
\end{aligned}
$$

Several techniques have been developed to surface passivate AlN powder against hydrolysis mostly by using hydrophobic coatings $[40,46,50,53]$. These hydrophobic coatings include long-chain organic molecules, such as carboxylic acids, particularly stearic acid, or cetyl alcohol, n-decanoic acid, dodecylamine acid and so on. However, these coating substances are not only environmentally un-friendly, but also hamper the dispersion ability of these coated powders in aqueous media and cause foaming of the suspensions leading to highly porous components after sintering. In a study, Shimidzu et al [40] used dicarboxylic acid (sebacic acid) in an attempt to protect AIN powder from hydrolysis and keep the hydrophilic carboxylic groups on the powder surface to facilitate the powder dispersion in water. Jon Binner and Yongheng Zhang [54] have studied the hydrolysis and dispersion behaviour of a commercial AIN powder protected against hydrolysis by silicone-based organic acid/ester hydrophobic coatings and an un-protected AlN powder using a commercial dispersing agent. The interactions between the long hydrocarbon chain and the underlying surface are regarded as the driving force for surfactant adsorption, with the lateral interactions between adsorbed molecules becoming increasingly important as adsorption density increased by covering the hydrophilic sites. However, the maximum achievable solids loading in aqueous suspensions upon using hydrophobized powders was found to be non-satisfactory. Therefore, there was still an open quest for finding suitable hydrophilic coating agents and treatment processes, which help dispersing the protected AlN powder in the aqueous medium and achieve satisfactory solids loading ( $\sim 50 \mathrm{vol} \%$ ) for colloidal processing.

The chemisorption of anions from poorly dissociated acids, such as phosphoric or silicic acids from aqueous environments, has also been reported to result in a high protection efficiency of AlN powders [55]. Krnel and Kosmac $[46,51]$ studied the hydrolysis behaviour of $\mathrm{AlN}$ at $\mathrm{pH} \sim 1$ and 3 by using several inorganic acids, which include $\mathrm{HF}$, $\mathrm{HCl}, \mathrm{HNO}_{3}, \mathrm{H}_{2} \mathrm{SO}_{4}, \mathrm{H}_{3} \mathrm{PO}_{4}$ and $\mathrm{Al}\left(\mathrm{H}_{2} \mathrm{PO}_{4}\right)_{3}$. At $\mathrm{pH} \sim 1$, an efficient stability against hydrolysis of AlN was observed regardless of the acid used. However, at $\mathrm{pH} 3$, the stability was found dependent on the nature of the acid used. The same authors also reported that $\mathrm{Al}\left(\mathrm{H}_{2} \mathrm{PO}_{4}\right)_{3}$ provided a very effective protective coating against hydrolysis on AlN powder [46]. However, the use of acid solutions at $\mathrm{pH}<2$ for treating large amounts of AlN powder is not advisable at least from the environmental point of view, and the resulting amount of phosphate species in the coating surface layer is also relatively high. The protection mechanism of AlN from hydrolysis by using phosphoric acid species is based on the reactions between these species and the surface hydroxyl groups, as described by equations (4) and (5) for Al surface sites with two bonds, or with a single bond, to the bulk particle, respectively $[46,51]$.

$$
\begin{aligned}
= & \mathrm{Al}(\mathrm{OH})+\mathrm{H}_{3} \mathrm{PO}_{4}+\mathrm{n}\left[\mathrm{Al}\left(\mathrm{H}_{2} \mathrm{PO}_{4}\right)_{3}\right] \\
& \rightarrow \mathrm{Al}\left(\mathrm{H}_{2} \mathrm{PO}_{4}\right)+\mathrm{n}\left[\mathrm{Al}\left(\mathrm{H}_{2} \mathrm{PO}_{4}\right)_{3}\right]+\mathrm{H}_{2} \mathrm{O} \\
& -\mathrm{Al}(\mathrm{OH})_{2}+2 \mathrm{H}_{3} \mathrm{PO}_{4}+\mathrm{n}\left[\mathrm{Al}\left(\mathrm{H}_{2} \mathrm{PO}_{4}\right)_{3}\right] \\
& \rightarrow \mathrm{Al}\left(\mathrm{H}_{2} \mathrm{PO}_{4}\right)_{2}+\mathrm{n}\left[\mathrm{Al}\left(\mathrm{H}_{2} \mathrm{PO}_{4}\right)_{3}\right]+2 \mathrm{H}_{2} \mathrm{O} .
\end{aligned}
$$

These equations suggest that 1-2 bulky phosphate anions bond to each single surface aluminium atom, thus, uniformly coating the surface of the particles and letting little chance for water molecules to come into contact and react with AlN. These phosphate anions interact preferentially with the hydroxyl groups of phosphate anions through hydrogen bonding. The hydrolysis resistance of AlN can also be improved by simple calcining it at about $600-800^{\circ} \mathrm{C}$. During this calcination process, a stable $\mathrm{Al}_{2} \mathrm{O}_{3}$ coating forms on the surface of each particle. However, the stability of the powder obtained by this route was insufficient to turn viable the aqueous processing [43,56]. Morisada et al [57] 


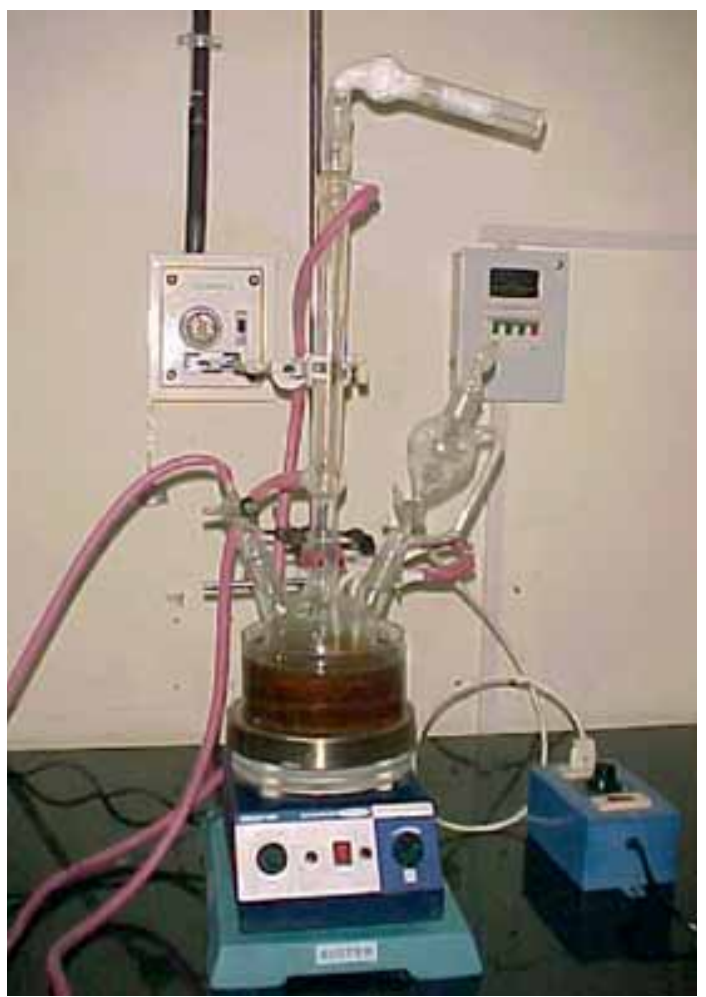

Figure 8. Experimental setup used for employing water-resistant coating on $\mathrm{AlN}$ as well as on $\mathrm{MgAl}_{2} \mathrm{O}_{4}$ spinel powders [15,43,47].

reported a process in which $\mathrm{SiO}$ coating was provided on AlN powder in vacuum at $1150-1450^{\circ} \mathrm{C}$ to protect it from hydrolysis.

Since all the above described techniques have been found to be either lengthy/cumbersome or involve capital-intensive equipment, we have developed a simple non-aqueous processing route for protecting AlN powder against hydrolysis and then successfully employed it for consolidating $\beta$ - $\mathrm{Si}_{4} \mathrm{Al}_{2} \mathrm{O}_{2} \mathrm{~N}_{6}$-radome structures with near-net shape by following aqueous colloidal processing routes $[15,19,43]$. In our process, $\mathrm{H}_{3} \mathrm{PO}_{4}$ and $\mathrm{Al}\left(\mathrm{H}_{2} \mathrm{PO}_{4}\right)_{3}$ were employed for providing the protective phosphate layer using a simple technique and process as shown in figure $8[15,43]$. The main advantage of this process is the formation of a single lamella of uni-molecular phosphate monolayer (figure 9) provided the exact amount (or even some excess) of coating agents are used [15,43]. The excess (un-reacted) coating agents can be eventually washed away by simply washing with ethanol from the powder surface. The ethanol used for washing purpose can also be separated from coating agents by a conventional distillation process and can be re-used several times for the same purpose. This differs from the aqueous acidic solution processing route that requires excess of $\mathrm{H}_{3} \mathrm{PO}_{4}$ or $\mathrm{Al}\left(\mathrm{H}_{2} \mathrm{PO}_{4}\right)_{3}$, which will remain on the powder surface.

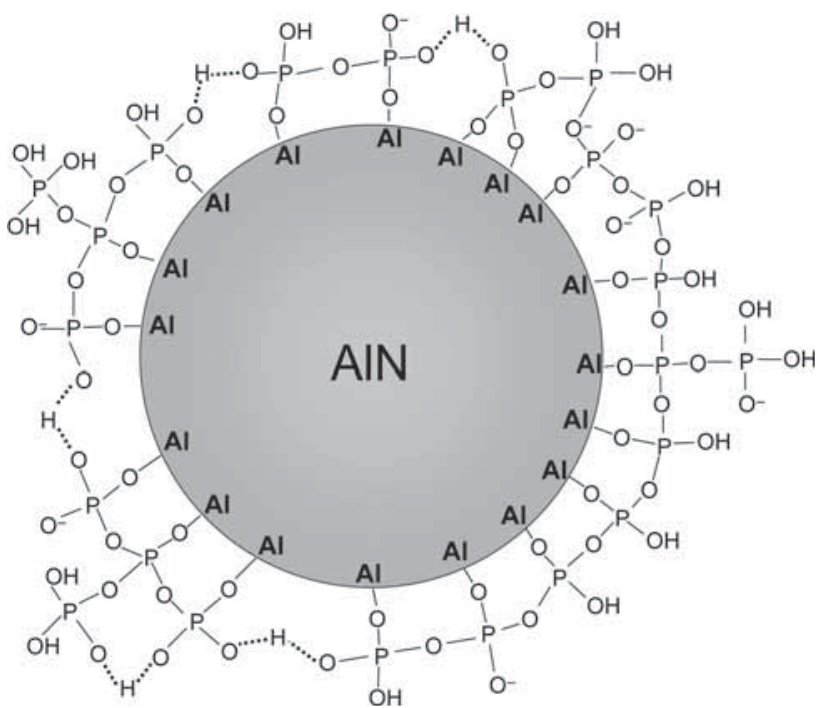

Figure 9. Schematic representation of the phosphate layer chemisorbed onto to the surface of an AlN powder particle [15,43].

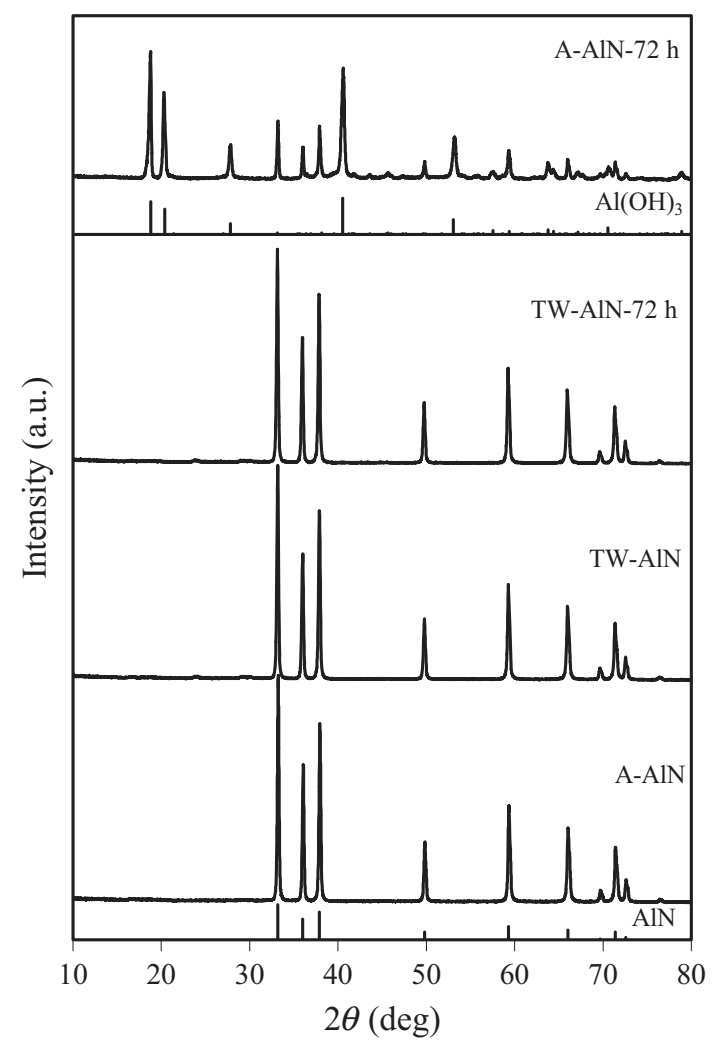

Figure 10. XRD patterns of as-purchased AlN (A-AlN) powder, treated and washed AIN (TW-AlN) powder, as-purchased AlN powder suspended in water for $72 \mathrm{~h}(\mathrm{~A}-\mathrm{AlN}-72 \mathrm{~h})$ and treated and washed AlN powder suspended in water for $72 \mathrm{~h}$ (TW-AlN-72 h) $[15,43]$.

The as-purchased (A-AlN) and the as-treated and washed (TW-AlN) AlN powders were characterized by various techniques before and after being suspended in water for $72 \mathrm{~h}$ (samples (A-AlN-72 h) and (TW-AlN-72 h), respectively) 
by XRD and other techniques (figure 10) [15,43]. As can be seen from these XRD patterns, the treated powder is quite stable against hydrolysis in water for more than $72 \mathrm{~h}$. This $72 \mathrm{~h}$ time period is very much sufficient to use this treated AlN powder, while processing SiAlON, AlN and AlON ceramic components by following aqueous colloidal processing routes.

\section{Aqueous colloidal processing of $\beta-\mathrm{Si}_{4} \mathrm{Al}_{2} \mathrm{O}_{2} \mathrm{~N}_{6}$ ceramics}

The surface-passivated AlN powder was employed against hydrolysis as one of the starting materials, the desired $\beta$ - $\mathrm{Si}_{4} \mathrm{Al}_{2} \mathrm{O}_{2} \mathrm{~N}_{6}$-precursor mixture was formulated and dispersed in the gelcast pre-mix solution [1] to consolidate dense ceramics. The properties of aqueous slurries and dense $\beta$ - $\mathrm{Si}_{4} \mathrm{Al}_{2} \mathrm{O}_{2} \mathrm{~N}_{6}$ ceramics consolidated by following an aqueous gelcasting process using 45, 48 and 50 vol\% solids-loaded suspensions containing $64.33 \mathrm{wt} \% \quad \alpha-\mathrm{Si}_{3} \mathrm{~N}_{4}, 23.36 \mathrm{wt} \%$ $\alpha-\mathrm{Al}_{2} \mathrm{O}_{3}, 9.37 \mathrm{wt} \%$ AlN and $7 \mathrm{wt} \% \mathrm{Y}_{2} \mathrm{O}_{3}$ and then sintered for $4 \mathrm{~h}$ at $1675^{\circ} \mathrm{C}$ have been published elsewhere [48]. The sintered stoichiometric $\beta-\mathrm{Si}_{4} \mathrm{Al}_{2} \mathrm{O}_{2} \mathrm{~N}_{6}$ formed from a $50 \mathrm{vol} \%$ solids-loaded slurry exhibited a hardness of $1423 \mathrm{Hv}$, a 3-point bend strength of $206 \mathrm{MPa}$, fracture toughness of $3.95 \mathrm{MPa}$ $\mathrm{m}^{-1 / 2}$, CTE of $3.372 \times 10^{-6}{ }^{\circ} \mathrm{C}^{-1}$ between 30 and $1000^{\circ} \mathrm{C}$, a dielectric constant of 7.22 at $17 \mathrm{GHz}$ frequency, whereas the sample consolidated by CDPP route exhibited the values of $1317 \mathrm{Hv}, 226 \mathrm{MPa}, 3.30 \mathrm{MPa} \mathrm{m}^{-1 / 2}, 3.532 \times 10^{-6}{ }^{\circ} \mathrm{C}^{-1}$ between 30 and $700^{\circ} \mathrm{C}$ and 7.206, respectively, after sintering under identical conditions [48]. This aqueous gelcast stoichiometric $\beta-\mathrm{Si}_{4} \mathrm{Al}_{2} \mathrm{O}_{2} \mathrm{~N}_{6}$ exhibited a 3 -point bend strength of $206 \mathrm{MPa}$, which is higher than the one exhibited by $\beta-\mathrm{Si}_{4} \mathrm{Al}_{2} \mathrm{O}_{2} \mathrm{~N}_{6}-0.5 \mathrm{SiO}_{2}(199 \mathrm{MPa})$. Although, small samples could be successfully consolidated with the desired density by following this conventional aqueous gelcasting route using the surface-passivated AIN powder against hydrolysis by following the process developed at ARCI, Hyderabad. The thin-wall components such as radomes, crucibles, etc., could not be fabricated successfully. This was due to the fact that insufficient strength was conferred to the green gelled parts by the employed gelcast monomers. Due to this poor strength, the gelled thin-wall components could not be taken out of the moulds without breaking [48].

As the hydrolysis-assisted solidification (HAS) technique is known for providing high strength to ceramic bodies formed in this process from aqueous slurries, we have also employed this HAS process to consolidate $\beta-\mathrm{Si}_{4} \mathrm{Al}_{2} \mathrm{O}_{2} \mathrm{~N}_{6}$ ceramics using the surface-passivated AlN as one of the starting raw materials as reported elsewhere [58]. The dense $\beta-\mathrm{Si}_{4} \mathrm{Al}_{2} \mathrm{O}_{2} \mathrm{~N}_{6}$ ceramics were consolidated by following this HAS route using aqueous slurries containing 48-50 vol\% solids, in which $5-22 \mathrm{wt} \%$ of the required $\alpha-\mathrm{Al}_{2} \mathrm{O}_{3}$ was replaced by equivalent amount of unprotected AlN powder to promote consolidation through AlN hydrolysis. A fixed amount (9.37 wt\%) of AlN powder passivated against hydrolysis according to the process developed at ARCI, Hyderabad, as a part of this project was also added to all the precursor mixtures consolidated by this HAS method [58]. The $\beta-\mathrm{Si}_{4} \mathrm{Al}_{2} \mathrm{O}_{2} \mathrm{~N}_{6}$ ceramics consolidated from slurries containing 49-50 vol\% of the HAS-5 precursor mixture in which $5 \mathrm{wt} \% \mathrm{Al}_{2} \mathrm{O}_{3}$ was replaced by an equivalent amount of unprotected AlN powder, exhibited superior properties (BD 3.15-3.32 $\mathrm{g} \mathrm{cm}^{-3}$, AP and WA of $0.0 \%$, contents of $\beta$-SiAlON $>93 \%$, hardness values of $1553-1590 \mathrm{~kg} \mathrm{~mm}^{-2}$ and fracture toughness $>3.40 \mathrm{MPa} \mathrm{m}^{-1 / 2}$ ) in comparison with $\beta-\mathrm{Si}_{4} \mathrm{Al}_{2} \mathrm{O}_{2} \mathrm{~N}_{6}$ ceramics consolidated by following the CDPP route [58]. Although the defect-free sintered $\beta-\mathrm{Si}_{4} \mathrm{Al}_{2} \mathrm{O}_{2} \mathrm{~N}_{6}$ rectangular bars with dimensions of $90 \times 55 \times 25 \mathrm{~mm}$ could be consolidated successfully by following this HAS route by replacing 5-10 wt\% alumina with unprotected AIN powder, the thin-wall components like crucibles, radome, etc., structures could not be fabricated as the cast parts were very hard after setting overnight and are brokent while un-moulding.

\section{Consolidation by hydrolysis-induced aqueous gelcasting process}

In 2009, the idea of hydrolysis-induced aqueous gelcasting (GCHAS) (figure 11), which is a combination of GC and HAS processes, was conceived by us for consolidating thin-wall complex-shaped ceramic components with near-net shape successfully from concentrated aqueous particulate slurries $[11,13,18-22,59]$. The limitation of this process is that it is suitable for only alumina, as a major or minor phase, containing ceramics. The synergetic effect of the combination of GC and HAS processes is (i) quick setting of slurry into a stiff gel under ambient conditions with an exceptionally high green strength, (ii) an absence of differential shrinkage during drying, and (iii) avoiding cracking of the part upon drying as water is partially consumed on hydrolysis of added $\mathrm{AlN}\left(\mathrm{AlN}+2 \mathrm{H}_{2} \mathrm{O} \rightarrow \mathrm{AlO}(\mathrm{OH})+\mathrm{NH}_{3}\right)$ to the slurry. The concomitant increase in $\mathrm{pH}$ of the slurry can also favourably change the permeability of the green bodies and minimize the thermal/moisture gradients. These advantages in turn enabled us fabricating defect-free ceramic components of all types (e.g., thick/thin and large/small). With this GCHAS process, dense and defect-free $\beta-\mathrm{Si}_{4} \mathrm{Al}_{2} \mathrm{O}_{2} \mathrm{~N}_{6}$ components including radome structures and crucibles have been successfully consolidated. The details of this GCHAS process vis-a-vis GC and HAS such as (i) the amount of time consumed in each process, (ii) the medium employed for slurry preparation, (iii) the condition of green radomes/crucibles/tubes and rectangular bars formed in each process, the solids loading and the absolute viscosity of slurry, etc., are published in refs. [19,59]. Normally, to obtain a defect-free consolidate by any colloidal processing route, the viscosity of the slurry should be kept $\leq 300 \mathrm{MPa} \mathrm{s}^{-1}$. Though GC is known for providing exceptionally high flexural strength to the green bodies, fabrication 


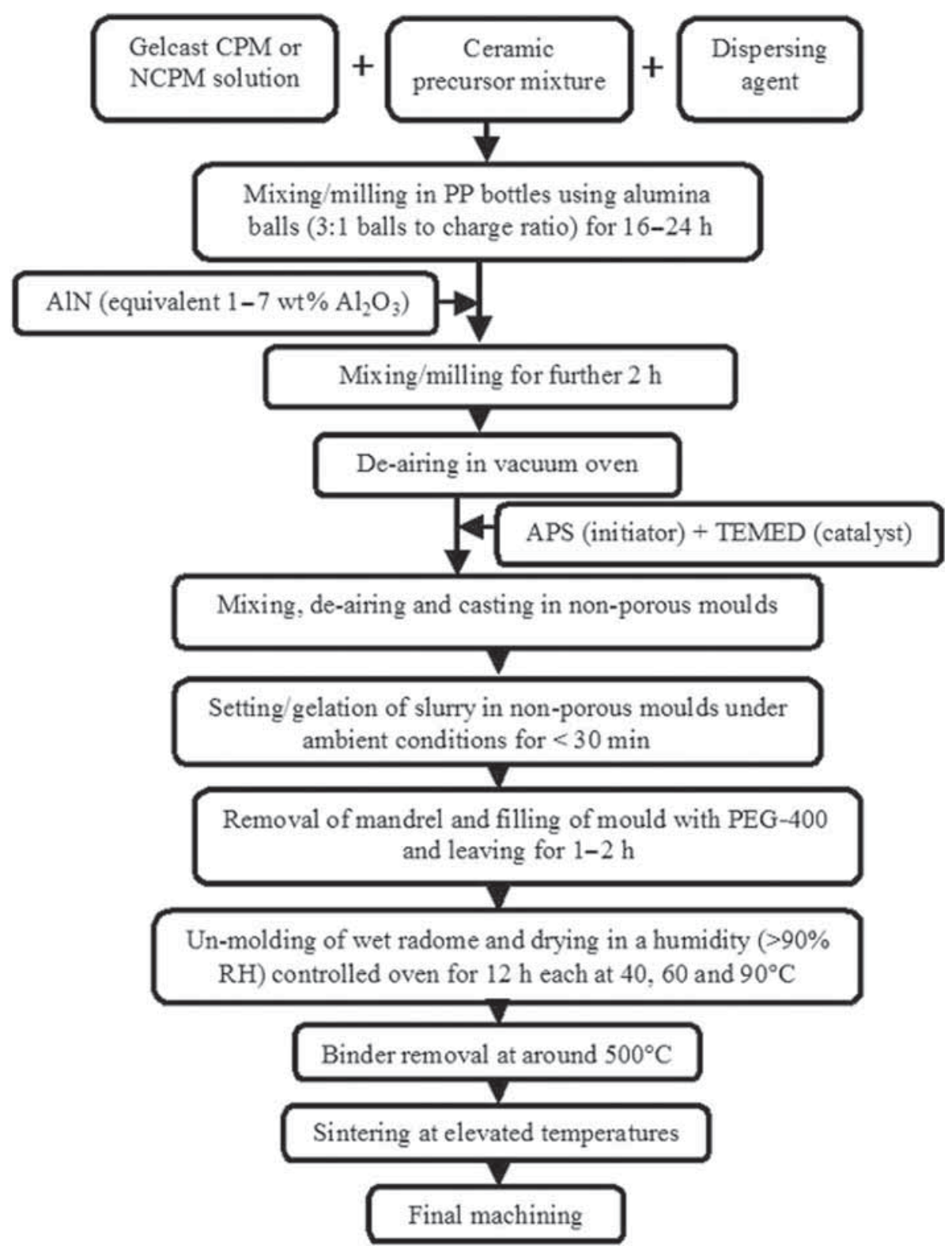

Figure 11. Hydrolysis-induced aqueous gelcasting (GCHAS) flowchart indicating various steps involved in it. CPM stands for conventional premix solution; NCPM for non-conventional premix solution; PP for polypropylene bottle; APS for ammonium persulphate; TEMED for tetramethylethylenediammine; and PEG-400 for polyethyleneglycol with 400 molecular weight $[11,13,18-22,59]$.

of certain structures, such as radomes, crucibles, tubes, etc., following this route is relatively difficult. This is due to the fact that the mandrel (figure 12) needs to be removed from the mould prior to the cast part gets completely gelled/dried, which causes breaking of the part within the mould due to excess shrinkage of the part when the solids loading in the slurry is not optimum [19,59]. The minimum solids loading required for making defect-free radomes, crucibles, tubes, etc., out of $\beta-\mathrm{Si}_{4} \mathrm{Al}_{2} \mathrm{O}_{2} \mathrm{~N}_{6}$ precursor mixture slurry was found to be 48 vol\%. When the solids loading was less than this ratio, the slurry took relatively more time to get gelled to the required extent. Further, in this case, the gelled parts were always found to be cracked as the mandrel could not allow the part to shrink to get enough strength $[19,59]$. The GCHAS slurries prepared with $20 \mathrm{wt} \%$ of organic monomers $(8.6 \mathrm{wt} \%$ MAM, $2.8 \mathrm{wt} \%$ MBAM and $8.6 \mathrm{wt} \% \mathrm{NVP}$ and $50 \mathrm{vol} \%$ solids loading, in which 5-7 wt $\% \mathrm{Al}_{2} \mathrm{O}_{3}$ replaced with equivalent amount of un-passivated AlN powder were found to be best for consolidating defect-free radome structures without any problem upon introduction of a $10 \mathrm{wt} \%$ APS and as-purchased 


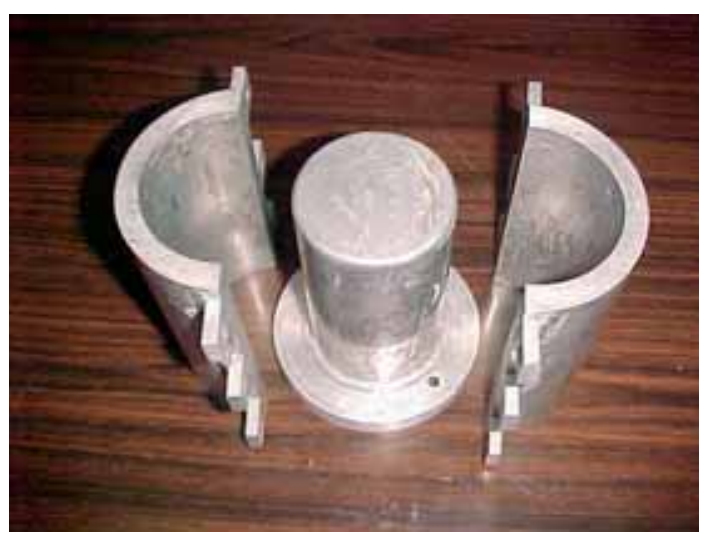

Figure 12. Split-type aluminium mould used for fabricating crucibles by following aqueous colloidal processing routes $[19,59]$.

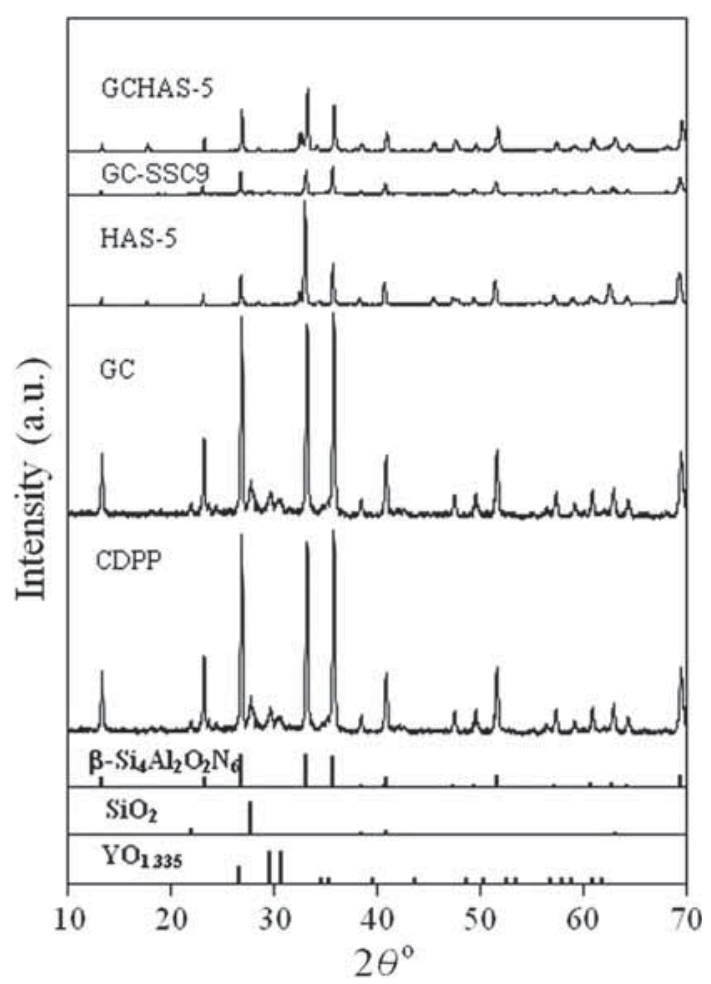

Figure 13. XRD patterns of sintered $\beta-\mathrm{Si}_{4} \mathrm{Al}_{2} \mathrm{O}_{2} \mathrm{~N}_{6}$ ceramics consolidated by following HAS (HAS-5), GC (GC), GCHAS (GCHAS5) and CDPP (CDPP) routes and of $\beta-\mathrm{Si}_{4} \mathrm{Al}_{2} \mathrm{O}_{-2} \mathrm{~N}_{6}-9$ wt $\% \mathrm{SiO}_{2}$ consolidated by GC route. $\mathrm{YO}_{1.335}$ (ICDD file no.: 00-039-1065); $\mathrm{SiO}_{2}$ (ICDD file no.: 01-085-0462); $\beta-\mathrm{Si}_{4} \mathrm{Al}_{2} \mathrm{O}_{2} \mathrm{~N}_{6}$ (ICDD file no.: 00-48-1616) [19,59].

TEMED at the ratio of 4 and $2 \mu \mathrm{g}^{-1}$ of particulate slurry, respectively, prior to casting in non-porous radome moulds [19,59].

XRD patterns of various $\beta-\mathrm{Si}_{4} \mathrm{Al}_{2} \mathrm{O}_{2} \mathrm{~N}_{4}$ ceramics sintered for $4 \mathrm{~h}$ at $1675^{\circ} \mathrm{C}$, and of $\beta-\mathrm{Si}_{4} \mathrm{Al}_{2} \mathrm{O}_{2} \mathrm{~N}_{4}-9 \mathrm{wt} \% \mathrm{SiO}_{2}$ ceramic composite sintered for $4 \mathrm{~h}$ at $1750^{\circ} \mathrm{C}$ are presented in figure 13
$[19,59]$. It can be seen that all the materials are fully crystalline and are mainly in the form of $\beta$-SiAlON phase (ICDD file no.: 00-48-1616) (>90\%). The formation of $\mathrm{Y}_{2} \mathrm{SiAlO}_{5} \mathrm{~N}$ (ICDD file no.: 00-048-1627) is expected in these materials due to the reactions that occur between $\mathrm{SiO}_{2}, \mathrm{Al}_{2} \mathrm{O}_{3}$ and $\mathrm{Y}_{2} \mathrm{O}_{3}$ during sintering at elevated temperatures; however, no characteristic XRD peaks due to this phase are noticed. The crystallite size of this material could be below the detection limit of XRD for not seeing any characteristic XRD peaks. However, some minor peaks due to $\mathrm{SiO}_{2}$ (ICDD file no.: 00-085-0462) and $\mathrm{YO}_{1.335}$ (ICDD file no.: 00-039-1065) are revealed by ceramics consolidated by following CDPP and GC ceramics. These latter phases are, in fact, the starting materials for $\mathrm{Y}_{2} \mathrm{SiAlO}_{5} \mathrm{~N}$ phase formation. These XRD results are well-comparable with those reported by Janney et al [1]. Though $\beta-\mathrm{Si}_{4} \mathrm{Al}_{2} \mathrm{O}_{2} \mathrm{~N}_{4}-9$ wt $\% \mathrm{SiO}_{2}$ ceramic composite contains $\sim 9 \mathrm{wt} \%$ free $\mathrm{SiO}_{2}$, no characteristics XRD peaks due to this excess silica are seen even after sintering for $4 \mathrm{~h}$ at $1750^{\circ} \mathrm{C}$. It has been reported that $\mathrm{SiO}_{2}$ formed by the surface oxidation of $\mathrm{Si}_{3} \mathrm{~N}_{4}$ is always in the form of amorphous state, and it reveals no characteristic XRD lines. Further, all these sintered materials exhibited reasonably high hardness $\left(1317-1571 \mathrm{~kg} \mathrm{~mm}^{-2}\right.$ ) and fracture toughness (3.30-3.95 $\mathrm{MPa} \mathrm{m}^{-1 / 2}$ ) values [19,59].

The SEM micrographs of $\beta-\mathrm{Si}_{4} \mathrm{Al}_{2} \mathrm{O}_{4} \mathrm{~N}_{6}$ ceramics consolidated by using $\mathrm{HAS}-5$, GC and GCHAS-5 precursor mixtures for $4 \mathrm{~h}$ at $1675^{\circ} \mathrm{C}$, and of $\beta-\mathrm{Si}_{4} \mathrm{Al}_{2} \mathrm{O}_{2} \mathrm{~N}_{6}-9 \mathrm{wt} \% \mathrm{SiO}_{2}$ ceramic composite formed from SSC9 precursor mixture for $4 \mathrm{~h}$ at $1750^{\circ} \mathrm{C}$ after consolidation by following different aqueous colloidal processing routes are presented in figure 14 [19,59]. It can be seen that ceramics formed in HAS (figure 14a) and GCHAS (figure 14c) processes consist almost a similar kind of microstructures comprising bimodal grains (one type is in the size range of $1-2 \mu \mathrm{m}$ and others in $\sim 5 \mu \mathrm{m}$ ) $[19,59]$. Very interestingly, the ceramic body formed in GC route (figure 14b) consists almost mono-model grains of hexagonal shape with 1-2 $\mu \mathrm{m}$ diameter and 5-10 $\mu \mathrm{m}$ length. Though, the $\beta-\mathrm{Si}_{4} \mathrm{Al}_{2} \mathrm{O}_{2} \mathrm{~N}_{6}-9 \mathrm{wt} \% \mathrm{SiO}_{2}$ ceramic composite (figure 14d) also consistssimilar type of grains, it has some additional grains with equi-axed shape [19,59]. Furthermore, this latter material consist some pores with $\sim 10 \mu \mathrm{m}$ diameter in size. These SEM micrographs of colloidal processed $\beta-\mathrm{Si}_{4} \mathrm{Al}_{2} \mathrm{O}_{4} \mathrm{~N}_{6}$ ceramics were compared very well with those reported for $\beta-\mathrm{Si}_{4} \mathrm{Al}_{2} \mathrm{O}_{4} \mathrm{~N}_{6}$ consolidated by CDPP $[38,60]$.

\section{7. $\beta-\mathrm{Si}_{4} \mathrm{Al}_{2} \mathrm{O}_{2} \mathrm{~N}_{6}-\mathrm{SiO}_{2}$ ceramic composites for radome applications}

Although $\beta-\mathrm{Si}_{4} \mathrm{Al}_{2} \mathrm{O}_{2} \mathrm{~N}_{6}-\mathrm{SiO}_{2}$ ceramic composites were reported to exhibit the best combination of properties for high speed radome applications [47], there was no straight forward route for their synthesis, and also for the fabrication of radome structures out of them. This is due to the fact that the $\beta$-SiAlON ceramic composites with greater than silica (i.e., 

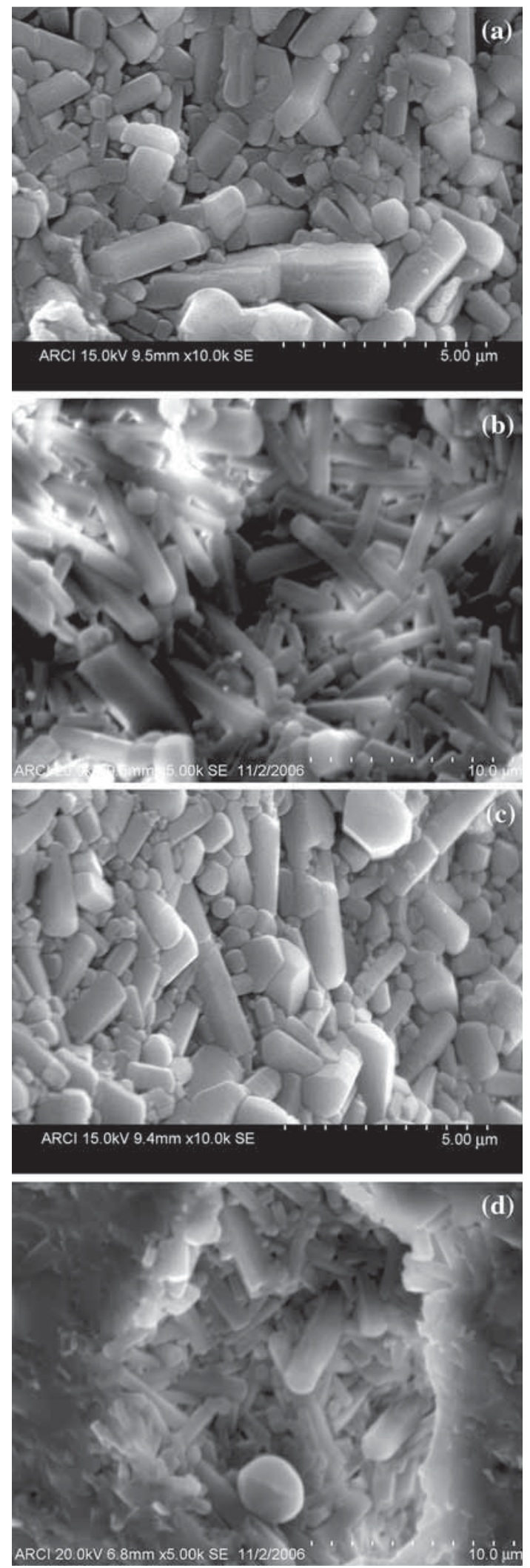

Figure 14. SEM micrographs of sintered $\beta-\mathrm{Si}_{4} \mathrm{Al}_{2} \mathrm{O}_{2} \mathrm{~N}_{6}$ ceramics consolidated by following (a) HAS, (b) GC and (c) GCHAS routes and (d) $\beta-\mathrm{Si}_{4} \mathrm{Al}_{2} \mathrm{O}_{-2} \mathrm{~N}_{6}-9 \mathrm{wt} \% \mathrm{SiO}_{2}$ consolidated by GC route $[19,59]$.
$>9 \mathrm{wt} \% \mathrm{SiO}_{2}$ ) cannot be prepared by following a conventional reaction sintering of $\mathrm{Si}_{3} \mathrm{~N}_{4}, \mathrm{AlN}$ and $\mathrm{Al}_{2} \mathrm{O}_{3}$ precursor mixtures, because they require an additional $\mathrm{SiO}_{2}$ as one of

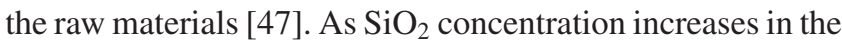
precursor mixture, the diffusion paths between reactive $\mathrm{Si}^{4+}$ and $\mathrm{Al}^{3+}$ species during sintering process also increase that restricts the formation of desired $\beta$-SiAlON phase, which is very important to confer high strength and toughness properties to these ceramics. As mentioned previously, Gilde et al [25] have prepared a silicon oxy-nitride ( $\mathrm{SiON}$ ) nanocomposite with a dielectric constant of 4.78 at $25^{\circ} \mathrm{C}$ and 5.0 at $1000^{\circ} \mathrm{C}$, and a loss tangent of 0.0014 at $25^{\circ} \mathrm{C}$ by calcining $\alpha$ $\mathrm{Si}_{3} \mathrm{~N}_{4}$ powder in an open-air atmosphere at $1700^{\circ} \mathrm{C}$ followed by fine grinding, compaction and re-sintering at $>1800^{\circ} \mathrm{C}$ in $\mathrm{N}_{2}$ atmosphere. However, this process does not yield any final product with consistent properties as its final chemical composition does not depend on the composition of precursor starting raw materials, but on the extent of oxidation of $\mathrm{Si}_{3} \mathrm{~N}_{4}$ powder that takes place upon calcination in air atmosphere. The oxidation of $\alpha-\mathrm{Si}_{3} \mathrm{~N}_{4}$ powder is highly influenced by several parameters such as atmospheric humidity, the degree of agglomeration of powder particles, temperature fluctuations in furnace, etc. Despite these problems, we have synthesized a ceramic composite with $\beta-\mathrm{Si}_{4} \mathrm{Al}_{2} \mathrm{O}_{2} \mathrm{~N}_{6}+9.0 \mathrm{wt} \% \mathrm{SiO}_{2}$ following a simple reaction sintering (for $4 \mathrm{~h}$ at $1750^{\circ} \mathrm{C}$ ) of $\mathrm{Si}_{3} \mathrm{~N}_{4} / \mathrm{Al}_{2} \mathrm{O}_{3}(=1.5)$ using $7 \mathrm{wt} \% \mathrm{Y}_{2} \mathrm{O}_{3}$ as a sintering aid (i.e., $1.5 \mathrm{Si}_{3} \mathrm{~N}_{4}+\mathrm{Al}_{2} \mathrm{O}_{3} \rightarrow \beta-\mathrm{Si}_{4} \mathrm{Al}_{2} \mathrm{O}_{2} \mathrm{~N}_{6}+0.5 \mathrm{SiO}_{2}$ ) [47]. Nevertheless, none of the combinations of $\mathrm{Si}_{3} \mathrm{~N}_{4}$ and $\mathrm{Al}_{2} \mathrm{O}_{3}$ can yield composites with $>9 \mathrm{wt} \% \mathrm{SiO}_{2}$. Of late, Advanced Materials Organization Inc., New York, has started producing radomes (with $25 \mathrm{~cm}$ height and $17.8 \mathrm{~cm}$ base diameter) with a chemical composition of $70 \mathrm{wt} \% \beta-\mathrm{SiAlON}+30 \mathrm{wt} \%$ fused silica for vehicles that travel at a speed of $>$ mach 5 . This ceramic composite exhibits a dielectric constant of 4.9 at $8.6 \mathrm{GHz}$, a flexural strength of $532 \mathrm{MPa}$ and a coefficient of thermal expansion (CTE) of $2.1 \times 10^{-6}{ }^{\circ} \mathrm{C}^{-1}$ [21]. However, this process involves two very complicated, cumbersome and expensive processing steps. Initially, a green radome is fabricated by following gelcasting of a non-aqueous slurry containing a precursor mixture $+30 \%$ organic fugitive material, followed by drying and sintering for $2-4 \mathrm{~h}$ at $>1750^{\circ} \mathrm{C}$ under a $\mathrm{N}_{2}$ pressure of $50-100$ bar to form $\beta$-SiAlON with $30 \%$ porosity. Then, this porosity is filled with a fused silica material by following a plasma spraying technique. Fused silica is added not only to reduce the dielectric constant from 7.3 to 4.2 , but also to reduce the density from 3.2 to $2.2 \mathrm{~g} \mathrm{~cm}^{-3}$, which is required for the targeted radome applications [21]. Nevertheless, introducing more than $30 \%$ porosity by utilizing organic fugitive material in gelcast $\beta$-SiAlON radomes is not an easy thing, particularly to have products with required product yield. In view of these difficulties in synthesizing $\beta$ SiAlON composites with higher than $30 \mathrm{wt} \%$ silica, we have developed a simple method to prepare $\beta-\mathrm{Si}_{4} \mathrm{Al}_{2} \mathrm{O}_{2} \mathrm{~N}_{6}-\mathrm{SiO}_{2}$ ceramic composites with $\mathrm{SiO}_{2}$ ranging 20-80 wt\% [61]. In our process, initially, a $\beta-\mathrm{Si}_{4} \mathrm{Al}_{2} \mathrm{O}_{2} \mathrm{~N}_{6}$ extrudates (figure 15) were prepared and then ground them to the desired fineness. 


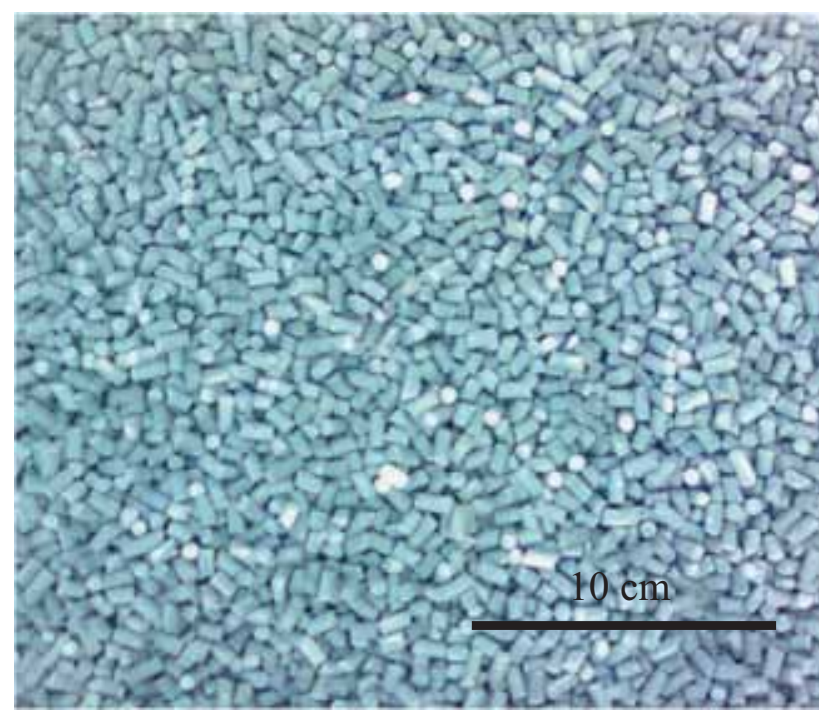

Figure 15. Extrudates of $\beta-\mathrm{Si}_{4} \mathrm{Al}_{2} \mathrm{O}_{2} \mathrm{~N}_{6}$ formed by reaction sintering of $\alpha-\mathrm{Si}_{3} \mathrm{~N}_{4}, \alpha-\mathrm{Al}_{2} \mathrm{O}_{3}$, surface-passivated $\mathrm{AlN}$ against hydrolysis and $\mathrm{Y}_{2} \mathrm{O}_{3}\left(7 \mathrm{wt} \%\right.$ sintering aid) at $1675^{\circ} \mathrm{C}$ for $4 \mathrm{~h}$ under $>800$ torr $\mathrm{N}_{2}$ pressure [61].

This fine ground powder can be mixed with different amounts of fused silica (0100 wt \%) and they can be compacted following any one of the consolidation techniques including CDPP, GC, HAS and GCHAS, and can be sintered for 3-4 h at $1500-1750^{\circ} \mathrm{C}$ to achieve the desired densification [61]. We found that among the different composites made from different compositions of $\beta-\mathrm{Si}_{4} \mathrm{Al}_{2} \mathrm{O}_{2} \mathrm{~N}_{6}$ and fused silica, the one formed out of $60 \mathrm{wt} \% \beta-\mathrm{Si}_{2} \mathrm{Al}_{2} \mathrm{O}_{2} \mathrm{~N}_{6}+40 \mathrm{wt} \%$ fused silica exhibited the best combination of sintered properties [61]. Owing to these reasons, a powder mixture containing $60 \mathrm{wt} \%$ $\beta-\mathrm{Si}_{2} \mathrm{Al}_{2} \mathrm{O}_{2} \mathrm{~N}_{6}+40 \mathrm{wt} \%$ fused silica was chosen for consolidation by following GCHAS process with the help of 1-5 wt $\%$ as-purchased AlN powder as a setting agent. The ceramics consolidated by following this GCHAS route are termed as SS40-1-SS40-5. The SS40 slurry containing $5 \mathrm{wt} \%$ AlN was found to be the best for fabricating near-net shape prototype radome structures. The dried radome structures were successfully sintered for $3 \mathrm{~h}$ at $1750^{\circ} \mathrm{C}$ in $\mathrm{N}_{2}$ atmosphere using a graphite mandrel (conformal sintering) as it is associated with a liquid-phase densification mechanism (figure 16) [21]. These sintered radomes were subjected to diamond grinding to obtain the final wall thickness and the shape. A dense SS40 composite obtained with $5 \mathrm{wt} \%$ AlN from 50 vol\% solids-loaded slurry in GCHAS process and sintering for $3 \mathrm{~h}$ at $1750^{\circ} \mathrm{C}$ exhibited a flexural strength of $\sim 140 \mathrm{MPa}$, Young's modulus of $213 \mathrm{GPa}$, CTE of $3.500 \times 10^{-6}{ }^{\circ} \mathrm{C}^{-1}$, hardness of $1390 \mathrm{~kg} \mathrm{~mm}^{-2}$, fracture toughness of $4.2 \mathrm{MPa} \mathrm{m}^{-1 / 2}$ and a dielectric constant of 5.896 [21].

Dielectric constant profiles of SS40-1-SS40-5 ceramic composite specimens sintered for $3 \mathrm{~h}$ at $1750^{\circ} \mathrm{C}$ are presented in figure 17 in the frequency range of $16.8-17.2 \mathrm{GHz}$ [21]. All these composites exhibited very stable and low dielectric constants in the range of 5.896-6.313 at $17 \mathrm{GHz}$ frequency. The $60 \mathrm{wt} \% \beta-\mathrm{Si}_{2} \mathrm{Al}_{2} \mathrm{O}_{2} \mathrm{~N}_{6}+40 \mathrm{wt} \%$ fused silica (SS-40) ceramic composite, $\beta-\mathrm{Si}_{2} \mathrm{Al}_{2} \mathrm{O}_{2} \mathrm{~N}_{6}(\mathrm{~S})$ and fused silica exhibited dielectric constant values of 6.03, 7.3 and 3.9, respectively, at $17 \mathrm{GHz}$ frequency [21]. Based on the rule of mixture, the SS-40 composite should exhibit a dielectric constant of 5.94. The dielectric constant of ceramic materials is not only influenced by chemical composition, but also by several other properties, such as frequency of applied field, temperature of the dielectric, humidity, crystal structure and other external factors including porosity. Since the applied frequency was varied through $16.8-17.2 \mathrm{GHz}$ at ambient temperature, the measured dielectric constant values can be originated by only electronic and ionic polarizations. In fact, the overall dielectric constant of any material is originated from different polarization mechanisms that include electronic polarization $\left(P_{\mathrm{e}}\right)$, ionic polarization $\left(P_{\mathrm{i}}\right)$, orientation polarization $\left(P_{\mathrm{o}}\right)$ and space charge polarization $\left(P_{\mathrm{sc}}\right)$. Out of which, polarizations from $P_{\mathrm{e}}$ and $P_{\mathrm{i}}$ are mostly compositiondependent, instantaneous, or nearly frequency-independent for most of the dielectrics and only marginally affected by temperature, whereas the $P_{\mathrm{o}}$ is both frequency-(time) and temperature-dependent. This polarization is slower than that of ionic polarization, and the $P_{\mathrm{sc}}$ is associated with ion migration, presence of grain boundary or inhomogeneous phases in the dielectric and is the slowest one. A closer look at data of figure 17 reveals that dielectric constant gradually decreases with the increase of added content of AIN into the precursor slurry [21]. Though porosity has contributed to some extent to the measured dielectric constant values, the dielectric constant was decreased along with porosity. This suggests that the decrease in dielectric constant with the increased content of AlN is primarily due to variation occurred in the chemical composition. The mass loss in SiAlON compounds at elevated temperatures was attributed to the evaporation of silicon mostly in the form of oxide as its vapour pressure at these temperatures is very low. Silica content increased with mass loss reduction and that could be the reason for lowering the dielectric constant values with the increase of AlN content in the starting precursor slurries. The dielectric constant of mullite, which is expected to form due to the reactions between $\mathrm{Al}_{2} \mathrm{O}_{3}$ and fused silica that occur during sintering process, is also lower (5.5) than that of $\beta-\mathrm{Si}_{4} \mathrm{Al}_{2} \mathrm{O}_{2} \mathrm{~N}_{6}$ at $\mathrm{GHz}$ frequency. These results indicate that the addition of $40 \mathrm{wt} \% \mathrm{SiO}_{2}$ into $\beta-\mathrm{Si}_{4} \mathrm{Al}_{2} \mathrm{O}_{2} \mathrm{~N}_{6}$ matrix can result in the reduction of the dielectric constant of SS-40 composite from 7.313 to 6.313, which was further reduced to 5.896 (for SS40-5) by the addition of $5 \mathrm{wt} \% \mathrm{Al}_{2} \mathrm{O}_{3}$ in the form of $\mathrm{AlN}$ powder [21,61]. Dielectric constant values in the range of 6.84-7.46 were reported for a gelcast $\beta-\mathrm{Si}_{4} \mathrm{Al}_{2} \mathrm{O}_{4} \mathrm{~N}_{6}$. The dielectric constant values (5.896-6.313) measured in this study for SS40-1-SS40-5 ceramic composites can be considered as highly promising [21].

The CTE profiles of SS40-1-SS40-5 ceramic composites sintered for $3 \mathrm{~h}$ at $1750^{\circ} \mathrm{C}$ are presented in figure 18 between 30 and $1000^{\circ} \mathrm{C}[21]$. These samples exhibited CTE values in the range of $3.50-4.016 \times 10^{-6}{ }^{\circ} \mathrm{C}^{-1}$. A gradual increase in 


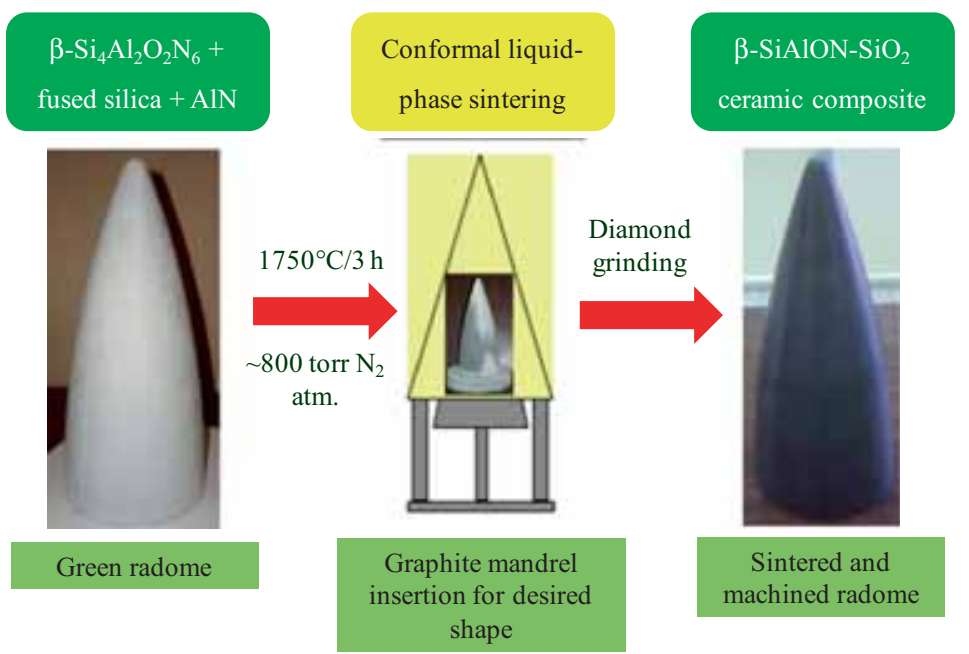

Figure 16. Conformal sintering process employed for liquid-phase sintering of prototype $\beta-\mathrm{SiAlON}-\mathrm{SiO}_{2}$ ceramic composite radome components consolidated by following hydrolysis induced aqueous gelcasting (GCHAS) of colloidal suspensions containing $50 \mathrm{vol} \%$ of $56.84 \mathrm{wt} \% \beta$ $\mathrm{Si}_{4} \mathrm{Al}_{2} \mathrm{O}_{2} \mathrm{~N}_{6}+37.89 \mathrm{wt} \%$ fused silica powder mixture $+5 \mathrm{wt} \%$ AlN (as purchased) at ARCI, Hyderabad. The organic premix solution was prepared by using total $20 \mathrm{wt} \%$ of organic monomers ( $8.6 \mathrm{wt} \%$ MAM, $2.8 \mathrm{wt} \%$ MBAM and $8.6 \mathrm{wt} \% \mathrm{NVP}$ ) and Dolapix CE64 as a dispersant employed at the rate of 10 $\mu \mathrm{g}^{-1}$ of powder mixture. The polymerization initiator (10 wt \% APS) and catalyst (as purchased tetramethylethylenediammine, TEMED) were introduced into the particulate suspension at the ratio of 4 and $2 \mu \mathrm{g}^{-1}$ of particulate slurry, respectively, prior to casting in non-porous radome moulds. After immediately pouring the slurry into the mould, the Teflon-coated steel mandrel was inserted into the slurry present in the mould.

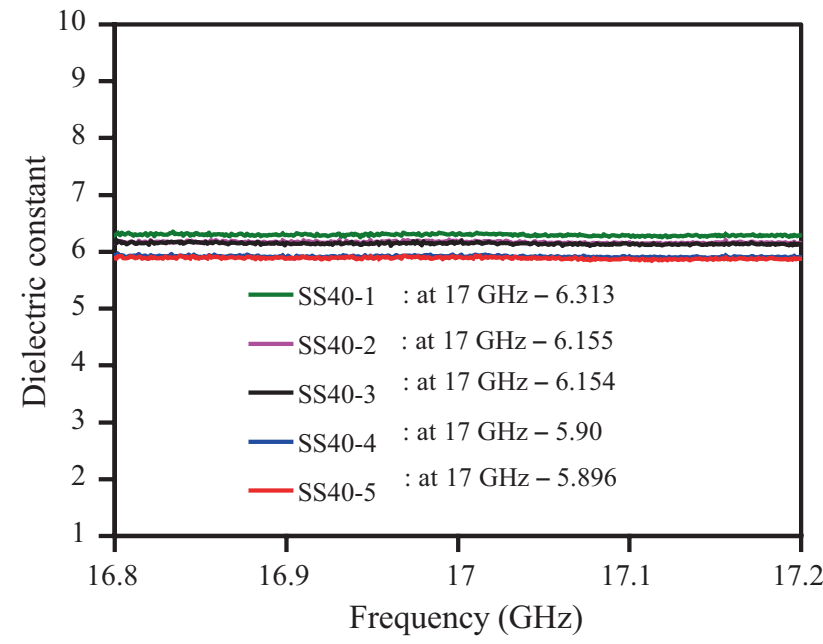

Figure 17. Dielectric constant profiles of SS40-1 to SS40-5 ceramic composites consolidated by following GCHAS of aqueous slurries containing 50 vol\% solids loading to which pure as-received AlN (equivalent to $1-5 \mathrm{wt} \% \mathrm{Al}_{2} \mathrm{O}_{3}$ ) was added and sintered for $3 \mathrm{~h}$ at $1750^{\circ} \mathrm{C}$ [61].

the CTE value from $3.766 \times 10^{-6}$ to $4.016 \times 10^{-6}{ }^{\circ} \mathrm{C}^{-1}$ with the increase of $\mathrm{AlN}$ equivalent to $1-3 \mathrm{wt} \% \mathrm{Al}_{2} \mathrm{O}_{3}$ and then a decrease of CTE (to $3.500 \times 10^{-6}{ }^{\circ} \mathrm{C}^{-1}$ ) with further increase

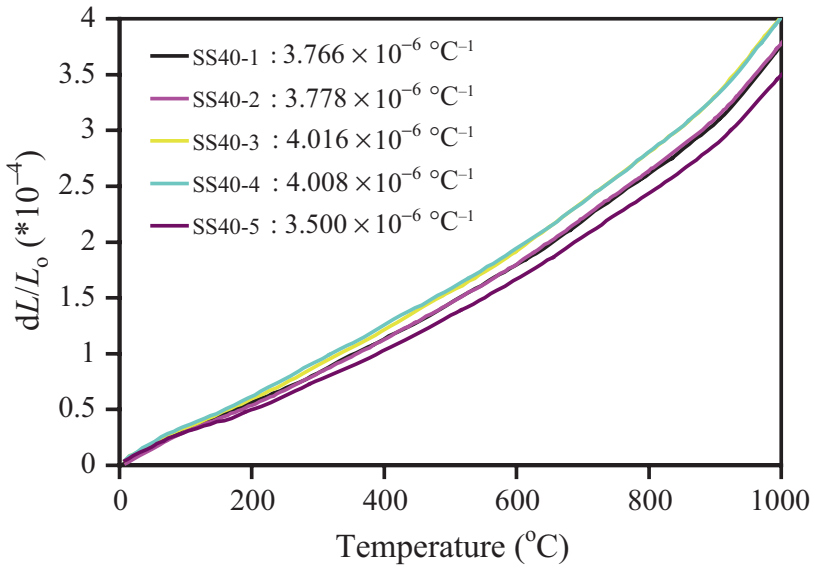

Figure 18. Coefficient of thermal expansion (CTE) profiles of SS40-1 to SS40-5 ceramic composites consolidated by following GCHAS of aqueous slurries containing $50 \mathrm{vol} \%$ solids loading to which pure as-received $\mathrm{AlN}$ (equivalent to $1-5 \mathrm{wt} \% \mathrm{Al}_{2} \mathrm{O}_{3}$ ) was added and sintered for $3 \mathrm{~h}$ at $1750^{\circ} \mathrm{C}$ [61].

of $\mathrm{AlN}$ equivalent to $5 \mathrm{wt} \% \mathrm{Al}_{2} \mathrm{O}_{3}$ can be seen. These changes are mainly attributed to the changes occurred in the chemical composition upon the addition of AlN into the starting precursor slurries. A gelcast $\beta-\mathrm{Si}_{4} \mathrm{Al}_{2} \mathrm{O}_{2} \mathrm{~N}_{6}$ exhibited a value 


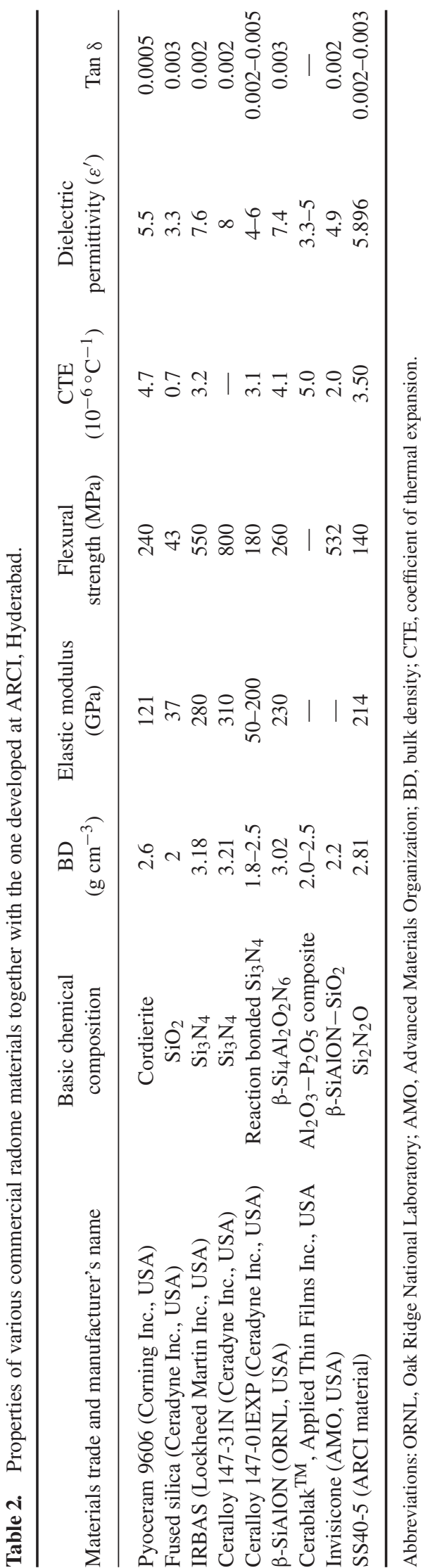

of $4.1 \times 10^{-6}{ }^{\circ} \mathrm{C}^{-1}$ between 25 and $1000^{\circ} \mathrm{C}$ [48]. A value of $2.1 \times 10^{-6}{ }^{\circ} \mathrm{C}^{-1}$ has been reported for $\mathrm{SiAlON}-\mathrm{SiO}_{2}$ composite having $30 \mathrm{wt} \% \mathrm{SiO}_{2}$ [47]. The values in the range of $3.532-4.657 \times 10^{-6}{ }^{\circ} \mathrm{C}^{-1}$ between 30 and $700^{\circ} \mathrm{C}$ have been measured for $\beta-\mathrm{Si}_{6-z} \mathrm{Al}_{z} \mathrm{O}_{z} \mathrm{~N}_{8-z}$ for which $z$ was varied from 1.5 to 4 [38]. Thus, the CTE values measured for SS40-1SS40-5 are quite encouraging for these ceramic composites to be employed as radome materials $[21,61,62]$.

Table 2 presents the basic chemical composition, BD, elastic modulus, flexural strength, CTE, dielectric permittivity and $\tan \delta$ of SS40-5 material (developed at ARCI, Hyderabad) and of several other commercial radome materials [21]. Materials trade names as well as the suppliers' and their corresponding countries names are also given in this table. In general, all the radome materials exhibited reasonably low $\mathrm{BD}$ values $\left(<3.2 \mathrm{~g} \mathrm{~cm}^{-3}\right)$, which are recommended for high speed radome materials. It can be seen that among various materials, only the $\mathrm{Si}_{3} \mathrm{~N}_{4}$ - and $\beta$ SiAlON-based materials exhibited relatively higher elastic modules and flexural strength values. Except Cerablak $^{\mathrm{TM}}$ $\left(5.0 \times 10^{-6}{ }^{\circ} \mathrm{C}^{-1}\right)$, Pyroceram $9606\left(4.7 \times 10^{-6}{ }^{\circ} \mathrm{C}^{-1}\right)$ and $\beta$-SiAlON $\left(4.1 \times 10^{-6}{ }^{\circ} \mathrm{C}^{-1}\right)$, all other materials exhibited relatively low CTE values $\left(<3.5 \times 10^{-6}{ }^{\circ} \mathrm{C}^{-1}\right)$. As far as the important dielectric permittivity property is concerned, the fused silica appears to have the best property as it has the value of only 3.3. The highest permittivity values are reported for $\beta$-SiAlON (7.4), the $\mathrm{Si}_{3} \mathrm{~N}_{4}$-based materials, IRBAS (7.6) and Ceralloy 147-31N (8). Nevertheless, all these materials exhibited considerably low $\tan \delta$ values $(<0.003)$. When compared to other materials, the SS40-5 possesses elastic modulus and flexural strength values that are almost three times higher than those of fused silica. The dielectric permittivity value of SS40-5 was measured to be 5.896, which is less than that of $\beta-\mathrm{Si}_{4} \mathrm{Al}_{2} \mathrm{O}_{2} \mathrm{~N}_{6}$ (7.4), IRBAS (7.6) and Ceralloy 147-31N (8). Based on these permittivity and flexural strength properties together with the high temperature $\left(>1300^{\circ} \mathrm{C}\right)$ withstanding and radome shape manufacturing capability, this SS40-5 can be considered as a candidate material of choice for certain high speed radome applications [21].

\section{Conclusions}

The following conclusions can be drawn from the work carried out as a part of developing the radome manufacturing process at ARCI, Hyderabad:

(1) $\beta-\mathrm{Si}_{4} \mathrm{Al}_{2} \mathrm{O}_{4} \mathrm{~N}_{6}$ composition out of wide-range solidsolution of $\beta-\mathrm{Si}_{6-z} \mathrm{Al}_{z} \mathrm{O}_{z} \mathrm{~N}_{8-z}$ (where $0 \leq z \leq 4.1$ ) can provide the best combination of properties in terms of structural, mechanical, dielectric and thermal properties as required by a radome used in high speed missile applications.

(2) An AlN-free precursor mixture of $\mathrm{Si}_{3} \mathrm{~N}_{4} / \mathrm{Al}_{2} \mathrm{O}_{3}(=1.5)$ can be employed to consolidate defect-free thin wall $\beta-\mathrm{Si}_{4} \mathrm{Al}_{2} \mathrm{O}_{4} \mathrm{~N}_{6}+0.5 \mathrm{~mol} \% \mathrm{SiO}_{2}$ composite ceramic 
components (for e.g., about $500 \mathrm{ml}$ capacity crucibles) by following a conventional aqueous gelcasting process.

(3) A non-aqueous surface-passivation technique developed at ARCI, Hyderabad, can be employed to passivate AlN and $\mathrm{MgAl}_{2} \mathrm{O}_{4}$ spinel powders against hydrolysis. These surface-passivated powders can be employed to consolidate complex-shaped components by following inexpensive and environmentally friendly near-net shape aqueous colloidal processing routes.

(4) The conventional aqueous gelcasting (GC) and hydrolysis-assisted solidification (HAS) processes cannot consolidate dense $\beta$-SiAlON ceramic structures, such as radomes, crucibles, etc., using the surfacepassivated AlN powder against hydrolysis as one of the starting raw materials.

(5) An hydrolysis-induced aqueous gelcasting (GCHAS), a novel near-net shaping colloidal processing route, designed and developed at ARCI, Hyderabad, can be employed to consolidate all kinds of defect-free components out of all the alumina containing ceramics, such as SiAlONs, alumina, $\mathrm{MgAl}_{2} \mathrm{O}_{4}$ spinel, $\mathrm{AlON}$, ZTA, mullite, cordierite, etc.

(6) The novel ceramic composites of $\beta$-SiAlON-fused silica $(20-80 \mathrm{wt} \%)$ can be synthesized by using $\beta$-SiAlON and fused silica powders as starting materials and can be consolidated by following GCHAS route. A $\beta$-SiAlONfused silica composite developed at ARCI, Hyderabad, exhibited properties on par with those exhibited by several commercial radome materials.

\section{Acknowledgements}

Author wishes to express his gratitude to all his colleagues at ARCI, Hyderabad, for their kind contributions to this study.

\section{References}

[1] Janney M A, Walls C A, Kupp D M and Kirby K W 2004 Am. Ceram. Soc. Bull. 839201

[2] Kirby K W, Jankiewicz A, Kupp D, Walls C and Janney M 2001 Mater. Technol. 16187

[3] Kirby K W, Jankiewicz A T, Lowell R F and Hallse R L 2000 In: Near net shape fabrication of ceramic radomes (USA: Raytheon Company) 8 pp

[4] Janney M A, Omatete O O, Walls C A, Nunn S D, Ogle R J and Westmoreland G 1998 J. Am. Ceram. Soc. 81581

[5] Janney M A, Kupp D M, Kirby K W and Walls C A 2003 Ceram. Trans. 142253

[6] Janney M A, Ren W, Kirby G H, Nunn S D and Viswanathan S 1998 Mater. Manuf. Process. 13389

[7] Omatete O O, Janney M A and Nunn S D 1997 J. Eur. Ceram. Soc. 17407

[8] Omatete O, Janney M A and Strehlow R A 1991 Am. Ceram. Soc. Bull. 701641
[9] Young A C, Omatete O O, Janney M A and Menchhofer P A 1991 J. Am. Ceram. Soc. 74612

[10] Ganesh I, Sundararajan G, Olhero S M, Torres P M C and Ferreira J M F 2010 Ceram. Int. 361357

[11] Ganesh I, Reddy G J, Sundararajan G, Olhero S M, Torres P M C and Ferreira J M F 2011 Int. J. Appl. Ceram. Technol. 8 873

[12] Ganesh I 2011 Ceram. Int. 372237

[13] Ganesh I 2011 Adv. Appl. Ceram. 110496

[14] Ganesh I, Olhero S M, Torres P M C and Ferreiraw J M F 2009 J. Am. Ceram. Soc. 92350

[15] Ganesh I, Olhero S M, Araujo A B, Correia M R, Sundararajan G and Ferreira J M F 2008 Langmuir 245359

[16] Ganesh I, Sundararajan G, Olhero S M and Ferreira J M F 2011 Ceram. Int. 37835

[17] Olhero S M, Ganesh I, Torres P M C, Alves F J and Ferreira J M F 2009 J. Am. Ceram. Soc. 929

[18] Ganesh I, Olhero S M, Torres P M C, Alves F J and Ferreira J M F 2009 J. Eur. Ceram. Soc. 291393

[19] Ganesh I 2009 Int. J. Appl. Ceram. Technol. 689

[20] Ganesh I 2011 Bull. Mater. Sci. 34327

[21] Ganesh I and Sundararajan G 2010 J. Am. Ceram. Soc. 93 3180

[22] Ganesh I, Reddy G J, Sundararajan G, Olhero S M, Torres P M C and Ferreira J M F 2010 Ceram. Int. 36473

[23] Kosmac T, Novak S and Sajko M 1997 J. Eur. Ceram. Soc. 17 427

[24] Novak S, Kosmac T, Krnel K and Drazic G 2001 J. Eur. Ceram. Soc. 22289

[25] Gilde G, Patel P, Hubbard C, Pothier B, Hynes T, Croft W et al 1997 US Patent, $5 \mathrm{p}$

[26] Harris J N and Welsh E A 1973 Fused silica design manual I. In: Georgia Inst. Technol. $151 \mathrm{p}$

[27] Kandi K K, Thallapalli N and Chilakalapalli S P R 2015 Int. J. Appl. Ceram. Technol. 12909

[28] Richardson K K, Freitag D W and Hunn D L 1995 J. Am. Ceram. Soc. 782662

[29] Gutierrez-Mora F, Goretta K C, Singh D, Routbort J L, Sambasivan S, Steiner K A et al 2006 J. Eur. Ceram. Soc. 261179

[30] Wang Y and Liu J 2009 Int. J. Appl. Ceram. Technol. 6190

[31] Wu J-H, Guo J-K and Li B 2000 J. Mater. Sci. 354895

[32] Wen G, Wu G L, Lei T Q, Zhou Y and Guo Z X 2000 J. Eur. Ceram. Soc. 201923

[33] Hsieh M Y 1987 Silicon nitride having low dielectric loss. In: GTE Products Corp., USA. 4 pp Cont.-in-part of U.S. Ser. No. 721,118

[34] Izhevskiy V A, Genova L A, Bressiani J C and Aldinger F 2000 J. Eur. Ceram. Soc. 202275

[35] Hampshire S, Park H K, Thompson D P and Jack K H 1978 Nature (London) 274880

[36] Jack K H 1976 J. Mater. Sci. 111135

[37] Oyama Y and Kamigaito O 1971 Jpn. J. Appl. Phys. 101637

[38] Ganesh I, Thiyagarajan N, Jana D C, Mahajan Y R and Sundararajan G 2008 J. Am. Ceram. Soc. 91115

[39] Jack K H 1978 Mater. Res. Bull. 131327

[40] Shimizu Y, Hatano J, Hyodo T and Egashira M $2000 \mathrm{~J}$. Am. Ceram. Soc. 832793

[41] Uno N, Enoki K and Miyakoshi M 1987 In: Surface treatment of aluminum nitride powder for improvement of water-repellency and -dispersibility (Japan: Furukawa Electric Co., Ltd.) $6 \mathrm{pp}$ 
[42] Ganesh I, Olhero S M and Ferreira J M F $2009 A d v$. Appl. Ceram. 108111

[43] Ganesh I, Thiyagarajan N, Sundararajan G, Olhero S M and Ferreira J M F 2008 J. Eur. Ceram. Soc. 282281

[44] Krnel K and Kosmac T 2006 Int. J. Mater. Res. 97645

[45] Olhero S M, Novak S, Oliveira M, Krnel K, Kosmac T and Ferreira J M F 2004 J. Mater. Res. 19746

[46] Krnel K and Kosmac T 2001 J. Eur. Ceram. Soc. 212075

[47] Ganesh I, Thiyagarajan N, Jana D C, Barik P and Sundararajan G 2008 J. Am. Ceram. Soc. 911566

[48] Ganesh I, Thiyagarajan N, Jana D C, Mahajan Y R and Sundararajan G 2008 J. Am. Ceram. Soc. 913121

[49] Sheppard L M 1990 Am. Ceram. Soc. Bull. 6911

[50] Groat E A and Mroz T J 1994 Am. Ceram. Soc. Bull. 7375

[51] Krnel K and Kosmac T 2000 J. Am. Ceram. Soc. 831375

[52] Koh Y-H, Choi J-J and Kirn H-E 2000 J. Am. Ceram. Soc. 83 306
[53] Shan H B, Zhu Y and Zhang Z T 1999 Br. Ceram. Trans. 98 146

[54] Binner J and Zhang Y 2005 Ceram. Int. 31469

[55] Fukumoto S, Hookabe T and Tsubakino H 2000 J. Mater. Sci. 352743

[56] Oliveira M, Olhero S, Rocha J and Ferreira J M F 2003 J. Colloid Interf. Sci. 261456

[57] Morisada Y, Sakurai T and Miyamoto Y 2004 Int. J. Appl. Ceram. Technol. 1374

[58] Ganesh I, Thiyagarajan N, Jana D C, Barick P, Sundararajan G and Ferreira J M F 2008 J. Eur. Ceram. Soc. 28879

[59] Ganesh I 2012 Mater. Manuf. Process. 27233

[60] Ganesh I, Thiyagarajan N, Jana D C, Sundararajan G, Olhero S M and Ferreira J M F 2008 J. Mater. Res. 232305

[61] Ganesh I and Sundararajan G 2011 Adv. Appl. Ceram. 110 87

[62] Ganesh I 2011 Process. Appl. Ceram. 5113 